\title{
Neurological disorders in HIV in Africa: a review
}

\author{
William P Howlett
}

1. Department of Internal Medicine, Kilimanjaro Christian Medical Centre, Moshi, Tanzania.

2. Center for International Health, University of Bergen, Norway.

\begin{abstract}
Background: Neurological disorders in HIV infection are a common cause of morbidity and mortality. The aim of this paper is to provide a narrative overview of up to date information concerning neurological disorders affecting HIV infected persons in Africa.

Methods: Seminal research concerning neurological disorders among HIV-infected adults in sub-Saharan Africa from prior to 2000 was combined with an in-depth search of PubMed to identify literature published from 2000 to 2017. The following Mesh terms were used. "Nervous System Diseases" "HIV Infections" and "Africa South of the Sahara" and "Seizures" or "Spinal Cord Diseases" or "Peripheral Nervous System Diseases" or "AIDS Dementia Complex" or "Opportunistic Infections" or "Immune Reconstitution Inflammatory Syndrome" or "Stroke". Only those articles written in English were used. A total of 352 articles were identified, selected and reviewed and 180 were included in the study. These included case series, observational studies, interventional studies, guidelines and reviews with metanalyses. The author also included 15 publications on the subject covering the earlier phase of the HIV epidemic in Africa from 1987 to 1999 making a total of 195 references in the study. This was combined with extensive personal experience diagnosing and treating these neurological disorders.

Results: Neurological disorders were common, typically occurring in WHO stages III/IV. These were in three main categories: those arising from opportunistic processes mostly infections, direct HIV infection and autoimmunity. The most common were those arising from direct HIV infection occurring in $>50 \%$. These included $\mathrm{HIV}$-associated neurocognitive dysfunction (HAND), neuropathy and myelopathy. Opportunistic infections occurred in $>20 \%$ and frequently had a 6-9-month mortality rate of $60-70 \%$. The main causes were cryptococcus, tuberculosis, toxoplasmosis and acute bacterial meningitis. Concurrent systemic tuberculosis occurred in almost $50 \%$.

Conclusion: Neurological disorders are common in HIV in Africa and the main CNS opportunistic infections result in high mortality rates. Strategies aimed at reducing their high burden, morbidity and mortality include early HIV diagnosis and anti-retroviral therapy (ART), screening and chemoprophylaxis of main opportunistic infections, improved clinical diagnosis and management and programme strengthening.

Keywords: Neurological disorders, HIV, Africa, opportunistic infections, direct HIV infection and inflammatory disorders.

DOI: https://dx.doi.org/10.4314/ahs.v19i2.19

Cite as: Howlett WP. Neurological disorders in HIV in Africa: a review. Afri Health Sci.2019;19(2):1953-1977. https:/ / dx.doi.org/10.4314/ abs.v19i2.19
\end{abstract}

\section{Introduction}

Neurological disorders (NDs) in persons infected with HIV are caused by three main mechanisms, direct HIV infection, opportunistic processes as a result of loss of cell mediated immunity, and inflammation or autoimmunity ${ }^{1}$.

\section{Corresponding author:}

William P Howlett,

Department of Internal Medicine,

Kilimanjaro Christian Medical Centre,

Moshi, Tanzania.

E-mail: williamhowlett.com@gmail.com
While they occur during all stages of HIV infection, they occur most frequently in advanced HIV disease where their overall pattern and frequency at clinical presentation is mostly a reflection of the person's level of immunity and previous environmental exposure1. NDs in persons with HIV in Africa are common, with opportunistic processes, mostly infections occurring in over one fifth of infected persons ${ }^{1-8}$ and neurological disorders/abnormal findings present in over two thirds in those with advanced disease ${ }^{24,28}$. Mortality caused by central nervous system (CNS) opportunistic infections (OIs) is particularly high in Africa with their reported 6-9-month case fatality rates

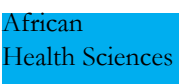

(C) 2019 Howlett WP. Licensee African Health Sciences. This is an Open Access article distributed under the terms of the Creative commons Attribution License (https://creativecommons.org/licenses/BY/4.0), which permits unrestricted use, distribution, and reproduction in any medium, provided the original work is properly cited. 
(CFR) of over sixty percent. This is in stark contrast to the much lower CFRs of around twenty percent for similar infections reported in high income countries (HICs). Among the main reasons for this threefold increase in mortality in Africa are late clinical presentation, advanced levels of immunosuppression and a high burden of frequently undiagnosed concurrent systemic infections, in particular tuberculosis (TB) and difficulties in diagnosis and treatment.

The overall aim of this paper was to review the main NDs occurring in adult persons infected with HIV in Africa in order to provide a practical framework for health care workers involved in managing and treating patients with the disease. In order to achieve this, the paper focusses on the following main objectives: measuring overall burden and documenting their aetiology, clinical presentations, diagnosis, management, outcome and prevention. The paper explores evidence starting with postmortems and mortality studies as the gold standard, followed by clinical studies. The main opportunistic processes are discussed; these include cryptococcal meningitis $(\mathrm{CM})$, tuberculous meningitis (TBM), acute bacterial meningitis (ABM), toxoplasma encephalitis (TE), syphilis and primary CNS lymphoma (PCNSL). The role of immune reconstitution inflammatory syndrome (IRIS) in CNS OIs is reviewed. The effects of direct HIV infection on the nervous system are presented including HIV associated neurocognitive dysfunction (HAND), neuropathies and myelopathies. Stroke seizures, paraplegia, radiculopathy and inflammatory neurological disorders are also discussed. Finally, a way forward outlines proposed intervention strategies aimed at reducing the mortality and morbidity of NDs in persons with HIV in Africa.

\section{Materials and methods}

This involves an analysis of the published literature including paper and electronic based journals and textbooks on the main neurological disorders(NDs) occurring in $\mathrm{HIV}$-infected adults $>18$ years of age in Africa. A search was made of published scientific literature using PubMed at the following webpage address: https://www. ncbi.nlm.nih.gov/pubmed. The following Mesh terms were used to search for relevant articles published from Jan 2000 up to July 2017: "Nervous System Diseases" "HIV Infections" and "Africa South of the Sahara" and "Seizures" or "Spinal Cord Diseases" or "Peripheral Ner- vous System Diseases" or "AIDS Dementia Complex" or "Opportunistic Infections" or "Immune Reconstitution Inflammatory Syndrome" or "Stroke". Only those articles written in English were used. A total of 352 articles were identified, selected and reviewed and 180 were included in the study. These included case series, observational studies, interventional studies, guidelines and reviews with metanalyses. The author also included 15 seminal publications on the subject covering the earlier phase of the HIV epidemic in Africa from 1987 to 1999 including articles, reviews and book chapters. A total of 195 references are presented in this paper. The author uses the clinical narrative based method for review and incorporates his knowledge, experience and discussions with colleagues and recognised experts. The term "Africa" is used throughout this paper to mean "Sub-Saharan Africa". This review refers to HIV-1 unless otherwise stated. The information presented in this paper follows the pattern of analysis of disease burden, aetiology, clinical presentation, management, outcome and strategies for prevention. A glossary of abbreviations is presented.

\section{Results \\ Mortality}

Infections are the leading cause of death in HIV infection with TB and pulmonary infections being the most common. In a review of the autopsies in Africa carried out in the pre-ART era tuberculosis (TB) was present in $37-57 \%$, involved two or more organs in $80-100 \%$ and considered to be the cause of death in $32-45 \%{ }^{1-8}$. In two more recent autopsy studies during the post-ART era using needle sampling TB was found to be present in $47-76 \%$ and to be the main cause of death ${ }^{4,9}$. A high burden of concordant bacterial infections 33-68\% was found in both those recent studies. Pneumonia was the second leading cause of death $20-25 \%$ with the reported frequencies of the individual causes: bacterial 9-39\%, pneumocystis carinii $9-14 \%$ and interstitial pneumonia $1-5 \%{ }^{3,4,6,7}$.

CNS infections were the third leading cause of death and accounted for $23 \%$ of all deaths in the first major autopsy series in Africa involving 294 cadavers $^{8}$. Reported frequencies of CNS/HIV infections in Africa ranged from $9-35 \%{ }^{5,6}$ with their overall frequency being approximately $20 \%{ }^{6}$. The main causes were cryptococcal meningitis (CM) 0-17\%, tuberculous meningitis (TBM) 6-11\%, acute 
bacterial meningitis (ABM) 2-9\% and toxoplasmosis encephalitis (TE) $0-15 \%{ }^{2,4-8}$. The frequencies of primary CNS Lymphoma (PCNSL) $0-1.4 \%$ and progressive multifocal leukodystrophy (PML) 0-1\% were generally low suggesting that these are relatively uncommon in Africa although a higher frequency of PML 3\% was reported in one small study ${ }^{5,6,8}$. The burden of previously undiagnosed disease discovered at autopsy was also large 45$49 \%$. These included TB 26-46\%, pneumonia 18-35\% and bacteraemia $33-68 \%{ }^{1-9}$. These were either not considered, unsuspected or wrongly diagnosed suggesting a leading role for multiple concurrent infections contributing to mortality in HIV in Africa. Together tuberculosis, bacteraemia/sepsis/pneumonia and CNS infections were responsible for over $80 \%$ of all HIV related deaths in Africa $^{5,6}$.

In keeping with the autopsy series clinical studies in Africa have also demonstrated that CNS infections are a major cause of death accounting for $>20 \%$ of HIV related deaths ${ }^{6,8,10,11}$. The case fatality rates (CFR) in individually treated CNS OIs are particularly high in Africa. In the pre-ART era, the pooled estimated " $6-9$ months" CFRs Africa were 68\% (9-70\%) for CM, 67\% (13-72\%) for TBM, 62\% (54-70\%) for ABM and 22\% (10-30\%) for TE with the majority of these deaths occurring during the first three months of illness. In the post ART era the pooled estimated "6-9 months" CFR post ART still remain high, CM 60\% and TBM 58\% with lower CFR rates reported in CM, 30-41\% and TBM 49\% when patients are optimally managed in clinical trial settings $\mathrm{s}^{4,11-22}$. Risk factors for death include advanced HIV infection, WHO stages III/IV, low CD 4 counts $<50$ cells $/ \mathrm{mm}^{3}$, altered mental status, seizures, lack of CSF pleocytosis and early initiation of ART during the course of the treated OI. The presence of concurrent infection in particular TB, frequently undiagnosed and unsuspected in up to $50 \%$ is a major contributor to the very high mortality reported in HIV in Africa $4,6,8,11,13,23,24$. In a review of patients started on ART in Africa a high overall mortality rate $8-26 \%$ was noted during the first 12 months of treatment, the majority dying within the first 3-6 months with TB and pneumonia as the leading causes ${ }^{25,26}$.

\section{Neurological Disorders (NDs)}

A high frequency $72-75 \%$ of NDs and abnormal neurological findings has been reported in clinical studies in HIV-1/AIDS in Africa ${ }^{24,27,28}$. The pattern of presentation of NDs is typically that of major NDs occurring in 10.5$22.2 \%$ of patients and a range of less obvious but more frequent NDs/abnormal neurological findings occurring in $34.4-75 \%$ of patients ${ }^{24,27-43}$. Major NDs include meningitis, altered level of consciousness, focal neurological disorders, stroke, seizures, myelopathy, radiculopathy and neuropathy and are caused by opportunistic processes, mostly infections, inflammation or infrequently by autoimmune inflammatory processes. In contrast, the less obvious but more frequent abnormal neurological disorders/findings are caused by the direct effects of the HIV virus itself and include HIV associated neurocognitive dysfunction (HAND), distal sensory neuropathy (DSN) and pyramidal weakness/signs secondary to vacuolar myelopathy (VM). In HIV-2 infected persons from West Africa a lower overall frequency of NDs has been reported, these include neurological impairment $10.3 \%$ and $\mathrm{CM}$ $4.6 \%,{ }^{44}$, however a high frequency of neuropathy $50 \%$, was reported in one study ${ }^{45}$.

These two main patterns of clinical presentations are clearly illustrated in a major study reported from South Africa involving a total of 506 consecutive inpatients presenting with advanced HIV (mean CD4 $=107$ cells $/ \mathrm{mm}^{3}$, range $<1-867)^{24}$. A total of seventy five percent were diagnosed with neurological illness. These included isolated NDs occurring alone as the presenting complaint in 11\% (mean CD4 $=143$ cells $/ \mathrm{mm}^{3}$ ) and NDs occurring in association with systemic illness occurring in 64\% (mean CD4 $=38$ cells $/ \mathrm{mm}^{3}$ ). A total of $32 \%$ had neurological illness as either the whole or part of the presenting complaint. CNS opportunistic infections (OIs) occurred overall in $20 \%$ of patients and included meningitis in $17 \%$ :(CM $7 \%$, TBM 6\%, and ABM 3\%, viral 1\%), tuberculoma $1 \%$, $\mathrm{TE}<1 \%$ and neurosyphilis (NS) $<1 \%$. The pattern of NDs also differed between the two main groups. In the group presenting with NDs alone OIs $81 \%$ and strokes $12 \%$ were the most common causes whereas NDs occurring as a result of direct HIV infection: HAND 4\% DSN $5 \%$ and VM $0 \%$ were distinctly uncommon. This was in contrast to NDs presenting in association with systemic illness where NDs resulting from direct HIV infectionwere the most common: HAND 59\%, neuropathy (DSN) $41 \%$ and vacuolar myelopathy (VM) $4 \%$ in contrast to those resulting from OIs $15 \%$ and strokes $1 \%$ which were much less frequent. The main non-neurological concurrent systemic illnesses were TB 46\%, gastroenteritis $15 \%$ and pneumonia $12 \%{ }^{24}$. 


\section{Opportunistic infections (OIs) Cryptococcal Meningitis (CM)}

Africa accounts for $>70 \%$ of the global burden of CM with almost 140, $000 \mathrm{CM}$ related deaths estimated to occur there annually ${ }^{46}$. It is the most common CNS OI in persons in HIV in Africa ${ }^{12,14,47-54}$ and is responsible for $10-20 \%$ of all HIV related deaths there ${ }^{12-14,46,53,55-59}$. In a review of 1303 cases of all cause HIV related meningitis in 7 countries in Africa CM accounted for 52\% (19-68\%), followed by TBM 19.6\% (1-36\%), ABM 14.2\% (6-30\%) and others $14.2 \%(7-49 \%)^{14}$. In a more recent study from SA, involving a large series of 11,891 cases of confirmed meningitis the main causes were CM 62.3\%, TBM 24.6\%, ABM $10.1 \%$ and others $2.1 \%{ }^{60}$. The reported frequency of $\mathrm{CM}$ in HIV varies within Africa from $3.25 \%$ in West Africa to $7 \%$ in Ethiopia, $40.4 \%$ in Uganda and 1.7-9\% in the Central African Republic with an overall estimated frequency there of $10.5 \%{ }^{12}$.

Clinically CM meningitis is characterized by a slow onset of symptoms of meningitis occurring over days or weeks (median 14 days) ${ }^{14,50,54,61-66}$. In areview of CM in Africa the main presenting clinical features were headache $62.5 \%$, fever $75 \%$ and meningeal signs $49 \%{ }^{12}$. In another large series involving 501 patients, mostly from Africa ${ }^{13}$ clinical features included headache $99 \%$, fever $57 \%$, nausea/ vomiting $54 \%$, visual symptoms $51 \%$, and seizures $19 \%$. Neurological signs in CM though frequently absent included neck stiffness $75 \%$, altered mental status $25 \%$, cranial nerve palsies (CNPs) 13\%, and papilloedema 12\%. Diagnosis is based on a combination of clinical findings and cerebrospinal fluid (CSF) examination. Lumbar puncture (LP) in CM typically reveals a CSF with an increased opening pressure $>20 \mathrm{cms}$, which is clear in appearance $75 \%(58-89 \%)$ with normal or elevated lymphocytes and protein. India ink staining is positive in $60-80 \%$ of cases on single CSF examination and $>90 \%$ on repeated examinations. Cryptococcal antigen $(\mathrm{CrAg}) /$ lateral flow assay (LFA) tests are positive in $>95 \%$ of cases $^{47,67-72}$.

The preferred treatment regimen for $\mathrm{CM}$ is in 3 phases: Induction phase with Amphotericin B $0.7 \mathrm{mg} / \mathrm{kg} /$ day $\mathrm{IV}+5$ Flucytosine $100 \mathrm{mg} / \mathrm{kg} /$ day administered orally for 14 days followed by consolidation phase with Fluconazole $400 \mathrm{mg} /$ day for 8 weeks or until CSF is sterile followed by a secondary suppressive phase of maintenance therapy with Fluconazole $200 \mathrm{mg}$ /day until CD4 counts are $>200 / \mathrm{mm}^{3}$. However, in the absence of Amphotericin B and Flucytosine the standard treatment for CM in many countries in Africa is with Fluconazole monotherapy $1200 \mathrm{mg}$ iv or oral once daily for 2 weeks followed by 8 weeks of consolidation phase and suppressive phase until CD 4 counts are $>200 / \mathrm{mm}^{3}{ }^{56}$. If the CSF pressure at diagnosis is elevated $(>20 \mathrm{~cm} \mathrm{H} 20)$ then serial daily/ alternate day lumbar punctures are indicated to decrease intracranial pressure) which has been shown to reduce mortality ${ }^{13,73}$. Routine steroids are not indicated in CM. Reported case fatality rates (CFR) are high in Africa 35$68 \%$ as compared to $14-26 \%$ in high income countries

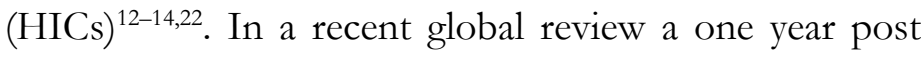
treated CM mortality rate of $70 \%(59-81 \%)$ was reported in low income countries, mostly in Africa ${ }^{46}$. However when managed optimally with fungicidal drugs (amphotericin based regimen) and delayed ART for 4-6 weeks after CM diagnosis in order to prevent immune reconstitution inflammatory syndrome (IRIS) significantly lower long-term CFRs of 30-41\% are reported in Africa ${ }^{13,16,74,75}$.

The main risk factors for death in $\mathrm{CM}$ in persons with $\mathrm{HIV}$ in Africa are advanced immunosuppression as measured by low CD 4 counts $\left(<50 / \mathrm{mm}^{3}\right)$, lack of access to rapidly acting fungicidal treatments such as Amphotericin B plus Flucytosine, starting ART treatment early within two weeks after CM diagnosis and treatment, IRIS and concurrent TB infection/nosocomial infections. The reported frequency of IRIS/CM occurring in Africa varies from $10-40 \%{ }^{4,76}$.

\section{Tuberculous Meningitis (TBM)}

$\mathrm{TB}$ is the most frequent $\mathrm{OI}$ in HIV in Africa occurring in over $50 \%$ of patients and accounting for $35-45 \%$ of all deaths there ${ }^{2,6,9,77}$. The main NDs arising from TB/HIV are meningitis (TBM), tuberculoma, myelo-radiculopathy and Potts disease of which TBM is the most common and associated with greatest morbidity and mortality. TBM is the second leading cause of meningitis in HIV patients in Africa after CM accounting for $10 \%$ of the TB/HIV cases and $>20 \%(1-36 \%)$ of all cause meningitis ${ }^{14,15,38,60,78,79}$. A higher frequency of $57 \%$ was reported in one more recent study in South Africa (SA) in the post ART era ${ }^{21}$.

In TBM the mean age of onset in adults ranges from 
26-37 years, the duration of symptoms ranged from 9-42 days. The clinical features are largely similar in TBM/ HIV and non-HIV ${ }^{78}$.

TBM/HIV presents with a subacute or chronic meningitis occurring over days or weeks.

Patients present typically with headache $40-100 \%$, fever 68-100\%, nausea/vomiting 26-50\%, seizures 3-50\%, meningeal signs $19-100 \%$, confusion, altered level of consciousness 30-70\%, and CNPs/focal neurological deficit $13-80 \%{ }^{78}$. Findings outside of the $\mathrm{CNS}$ are more common in TBM/HIV than in TBM/non-HIV including multiorgan TB dissemination and anaemia in most patients. Clinical algorithms predicting TBM have low sensitivity $78 \%$ and specificity $43 \%$ in populations with high seroprevalence of $\mathrm{HIV}^{78,80}$. This is partially explained by the other infections, in particular cryptococcus presenting with similar symptoms and signs and the clinical differential diagnosis includes all causes of meningitis in HIV.

The diagnosis of TBM particularly in HIV is often presumptive based on a combination of clinical, laboratory and radiological findings. In TBM/non-HIV the CSF is typically clear or slightly yellow but on microscopy shows elevated leukocytes, mostly lymphocytes, raised protein and decreased glucose ( $<50 \%$ blood glucose). However, in TBM/HIV the CSF may be normal microscopically in $10-20 \%$ of cases particularly in advanced immunosuppression, and neutrophils rather than lymphocytes may predominate, particularly in TBM-IRIS. Direct acid-fast bacilli (AFB) smear has a low overall sensitivity of 10$20 \%$ in TBM unless large volumes of CSF ( $>7 \mathrm{mls}$ ) are used and increased time ( $>30$ mins) is spent on microscopy $^{14}$. The rate of TB positive CSF culture rate in TBM/ HIV $42 \%$, is higher as compared to TBM/non-HIV 30\%, because of abundant organisms but the result may take one to four weeks. There has however been a significant improvement in the laboratory diagnosis of TBM with the use of newer point of care (POC) rapid diagnostic tests. These tests include Gene Xpert MTB/RIF (Xpert), with a sensitivity of $27-86 \%$ and specificity of $95-100 \%$, and lipoarabinomannan (LAM) lateral flow assay (LFA) and LAM antigen detection enzyme-linked immunosorbent assay (ELISA), sensitivities 29-70\%, and specificity $93 \%$, in advanced HIV ${ }^{14,81}$. When using centrifuged CSF in TBM/HIV Xpert has consistently high sensitivities 72$82 \% 82,83$ and although a significant improvement on culture it cannot be used to rule out TBM. POC tests with their increased sensitivities and high specificities in proven TBM have an important role in the diagnosis of TBM and Xpert is recommended by WHO for use in Africa ${ }^{81}$. Radiological findings indicate that TBM/HIV patients are more likely to have disseminated extra pulmonary TB with an abnormal chest X-ray reported in 53-67\% ${ }^{78}$. On neuroimaging, abnormal findings suggestive of TBM brain are present in $55-100 \%$ of cases. These include basal meningeal enhancement, infarction and tuberculomas and are found with the same frequency as in TBM/nonHIV but hydrocephalus is notably less common in TBM/ HIV $0-6 \%$ v $20-64 \%{ }^{78}$.

Current management of TBM/HIV is similar to TBM/ non-HIV and involves treatment with the standard TB drugs, rifampicin, isoniazid, pyrazinamide and ethambutol for 2 months followed by rifampicin and isoniazid for a period of 10 months. Studies in TBM/non-HIV evaluating the use of higher doses of rifampicin $(>10 \mathrm{mgs} / \mathrm{kg})$ administered intravenously or orally and the additional use of fluoroquinolones have conflicting results and have yet to be evaluated in TBM/HIV. The role of anti-inflammatory treatment with steroids is of uncertain benefit in TBM/HIV although their use in TBM/non-HIV is recommended for a total period of 8 weeks, the main danger being increased risk of other infections. Multi drug resistant (MDR) TB is more common in TBM/ HIV $13-17 \% \%$ versus TBM/non-HIV 4\%, particularly in those patients with a history of previously treated TB $8-58 \%{ }^{78,84}$. Mortality in MDR/TBM is $100 \%$ unless managed early and treated appropriately with second line drugs. Surgery may be indicated in a small number of TBM/HIV cases for mass lesions and hydrocephalus but has a particularly high mortality. Starting ART during TB treatment reduces mortality but it is recommended to delay starting ART until 4-6 weeks after starting TB treatment in order to decrease the risk of IRIS ${ }^{17}$.

TBM has a high CFR in Africa, 59.9\% $(40.3-87.9 \%)^{15}$. In a global review of treated TBM/HIV meningitis ${ }^{21,78}$ the in-hospital CFR ranged from 13-72\% and the 6-9 month CFR was $41-67 \%$ with the highest rates $>60 \%$ reported from Africa. In a retrospective study in SA the 9 month post ART CFR in optimally treated TBM was $49 \%$ with $12 \%$ lost to follow up ${ }^{17}$. The main risk factors for early death in TBM in Africa included late clinical stage; British Medical Research Council grades II \& III, advanced im- 
munosuppression, and CD $4<50$ cells $/ \mathrm{mm}^{3}$ at presentation. Notably HIV related concurrent illness accounts for up to $50 \%$ of all-cause mortality in TBM/HIV patients not on ART who don't survive. Reported IRIS rates in TBM/HIV in Africa are $8-43 \%{ }^{17,78,85}$.

\section{Acute Bacterial Meningitis (ABM)}

The risk of acute bacterial meningitis (ABM) is significantly increased in HIV infection in Africa and accounts for approximately 14\% (6-30\%) of all cause HIV/meningitis ${ }^{14,60}$. The relative risk of pneumococcal meningitis (PM) is significantly higher in HIV than in the general population $^{14,18}$. In Malawi, out of a total of 715 cases of ABM, $87 \%$ of whom were HIV infected, $84 \%$ were caused by $S$. pneumoniae and $4 \%$ by $N$. meningitides ${ }^{18}$. The main clinical features in that series were similar in ABM/ $\mathrm{HIV}$ and in ABM/non-HIV patients and included headache/meningism $99 \%$, fever $86 \%$, seizures $45 \%$ and confusion/altered level of consciousness $44 \%$ median Glasgow Coma Scale (12/15). The 10 and 40-week CFRs of $45 \% / 53.4 \%$ reported in that series were independent of HIV status ${ }^{18}$.

\section{Toxoplasmosis Encephalitis (TE)}

Toxoplasma encephalitis (TE) is the most common CNS $\mathrm{OI}$ in HIV in HICs. The incidence and prevalence vary significantly across continents and within individual countries with worldwide toxoplasma $\mathrm{IgG}$ seroprevalence rates varying from 20 to $75 \%$. A similar pattern exists within Africa ranging from 29\% in Gauteng province SA to 34\% in Kwa-Zulu Natal SA and 46-94.4\% reported in Ethiopia with particularly high rates in HIV infected cohorts $^{32,87,88}$. Toxoplasmosis and HIV co-infected persons are at increased risk of developing TE with the majority of TE cases $85-95 \%$, due to reactivation, mostly affecting the CNS with very occasional involvement of retina and lungs. The reported frequency of TE in HIV varies significantly within Africa from $0-1 \%$ in parts of SA/Botswana/Uganda/Malawi to $2.7 \%$ in Kenya and increases to $10 \%$ in West Africa and Ethiopia ${ }^{2,6,11,32,89,90}$. In the post ART era in Africa the reported frequency varies from $0-10 \%$ with the highest rates in West Africa ${ }^{11}$. A recent report from Gabon in West Africa reported TE as accounting for two thirds of CNS/HIV infections 91. The main risk factors for TE are low CD4 counts of $<200$ cells $/ \mathrm{mm}^{3}$ and the presence of a positive toxoplasma $\operatorname{IgG} / \operatorname{IgM}$ serology.
The main clinical features of TE are headache and fever 40-93\% coupled with focal neurological signs; hemiparesis/cranial nerve palsies $50-73 \%$, seizures $30-58 \%$ and confusion/lethargy 31-40\% developing sub-acutely usually over weeks or more uncommonly days ${ }^{19,20,32,92}$. Treatment is with high dose trimethoprim-sulphamethoxazole for 4 weeks followed by continuation phase for 8 weeks and then maintenance therapy until CD 4 counts $>200$ cells $/ \mathrm{mm}^{3}{ }^{93}$. Steroids are not recommended. Post starting treatment there is typically clinical improvement by day 3 in $50 \%$ and by day 14 in 90\% with complete resolution in $90 \%$ within 6-26 weeks ${ }^{32}$. The diagnosis of TE is based on clinical features, the presence of a focal neurological deficit, IgG antibodies, the finding of a ring enhancing lesion(s) on CT and response to treatment. Typical CT findings are those of single or multiple hypodense $>5 \mathrm{~mm}$ ring enhancing lesions with edema in the basal ganglia and or in the grey/white matter zone present in $>80 \%$ of cases. Radiological improvement usually occurs by the third week of treatment. The main differential diagnosis for any focal brain lesions in HIV in Africa includes toxoplasmosis, tuberculoma and cerebral lymphoma ${ }^{38}$. As a general guide to their diagnosis a CD4 count in the range of $100-200$ cells $/ \mathrm{mm}^{3}$ suggests TE, while a CD 4 count of $<50$ cells $/ \mathrm{mm}^{3}$ suggests primary CNS lymphoma (PCNSL) and a CD4 $>200$ cells $/ \mathrm{mm}^{3}$ suggests tuberculoma.

CFR in treated Toxo/HIV in Africa is $10-30 \%{ }^{19,20}$, with a higher rate of $44.1 \%$ reported in one study in Ethiopia ${ }^{22}$. CFRs one year after infection range from $20-60 \%$ with the higher rates reported in resource poor settings ${ }^{68}$.

\section{Immune reconstitution inflammatory syndrome (IRIS)}

The immune reconstitution inflammatory syndrome (IRIS) is an exaggerated activation of immune system with increased inflammatory response against persisting antigen (paradoxical) or pathogens (unmasking). It is characterized by deterioration clinically and radiologically after a period of initial improvement following initiation of ART treatment. Its onset is very variable from a few days to 3 months and rarely 6-12 months after starting $\mathrm{ART}^{26}$. Its overall frequency in the first 6 months of ART in HIV in Africa is estimated to be around $10 \% 0^{26,76,94}$ with higher rates reported in TB $15.7 \%(9.7-24.5 \%)^{95}$. In a recent autopsy series in SA, IRIS was reported as contributing to $73 \%$ of early ART mortality ${ }^{3}$. The main risk fac- 
tors for IRIS are degree of immunosuppression including low CD4 $\left(<50\right.$ cells $\left./ \mathrm{mm}^{3}\right)$, high viral load, high antigenic burden or disseminated OI and shorter duration of OI/ ART treatment. CNS IRIS contributes to most of the burden of IRIS and mortality attributed to CNS/IRIS is high $13-30 \%$ depending on type. The main causes of CNS/IRIS are CM and TBM and less frequently PML. IRIS is uncommon in TE and is unmasking rather than

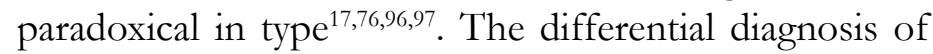
IRIS includes other concurrent CNS infections, MDR in $\mathrm{TB}$, lack of compliance, drug reactions and toxicities.

Cryptococcal CM/IRIS occurs with a frequency of $21 \%$ (13-45\%) in those patients who start ART soon after treatment for $\mathrm{CM}^{76}$. It occurs typically 4-9 weeks post ART initiation with a median of 29 days (range 23-45 days) reported in one study ${ }^{13}$. CM/IRIS is most commonly paradoxical but can also be unmasking in a small number, $(1 \%)$ of patients starting ART. It occurs in a significantly larger number of those with subclinical cryptococcal antigenemia ${ }^{47,68}$. Clinical features are those of a recurrence of meningeal symptoms, headache, and visual disturbances, vomiting along with impaired consciousness, seizures and occasionally focal neurology. Non-neurological presentations are less common and include lymphadenitis, pneumonitis and ophthalmic involvement. Mortality attributed to IRIS in CM is estimated to be around 20\% $(13-36 \%)^{55,76,95}$, although no increased mortality was reported in one large study involving 266 patients from SA with $\mathrm{CM}^{13}$. Risk factors for IRIS include abnormal mental status, high baseline fungal burden load and low CD4 count at onset and early ART treatment. The timing of ART is important and based on randomized controlled studies in Uganda and SA using delayed ART mortality rates decreased from $45 \%$ to $30 \%{ }^{16}$. Treatment of IRIS is in the usual way for $\mathrm{CM} / \mathrm{HIV}$ with antifungals, repeated LPs and steroids if severe. Specific strategies to decrease CM/IRIS include delaying ART until 4-6 weeks after initiating CM treatment.

TB-IRIS occurs with an overall frequency $>15 \%$ in TB/ HIV patients of which approximately $75 \%$ is paradoxical and $25 \%$ unmasking ${ }^{95}$. Neurological TB-IRIS accounts for overall $12 \%$ of all TB-IRIS. Its onset is variable but in a recent prospective study in SA involving steroid treated previously ART-naive culture confirmed TBM/HIV patients, a high rate of TBM-IRIS 47\% was reported at a median of 14 days (range 4-20) after starting ART $^{17}$. Treatment of TBM-IRIS in that study involved standard TB drugs, delayed ART and the use of steroids for 109 days (range 69-141 days) ${ }^{17}$. Mortality attributable to TBM-IRIS at 9 months was $13 \%{ }^{17}$. The clinical features in TBM/IRISare those of a worsening of the underlying TBM including headache, meningism, confusion, vomiting and seizures or of tuberculoma spinal TB or systemic TB. Risk factors for developing TBM-IRIS include: disseminated TB, a shorter time interval from starting anti TB to ART treatment ( 2 weeks), severe immunosuppression, a rapid immune recovery, and high CSF cell counts, in particular neutrophils, activated innate immunity ${ }^{98}$ and a positive TB/CSF culture. Specific strategies to decrease TBM-IRIS include delaying starting ART prophylaxis until 4-6 weeks after initiating TB treatment.

\section{Neurosyphilis (NS)}

The overall global burden of syphilis is 12 million new cases of primary infection every year approximately two thirds of which are in Africa and South East Asia ${ }^{99}$. The reported seroprevalence of syphilis in Africa is high, varying between $2-17 \%$ in antenatal clinics and $7-10 \%$ in HIV patients ${ }^{100}$. Despite the high burden of primary syphilis in Africa there are few published reports of neurosyphilis in HIV and those suggest a low overall burden. One large study from SA involving 506 patients presenting with AIDS reported just a single case ${ }^{24}$. In a large study in SA involving ${ }^{4,549}$ adults presenting with meningitis a diagnosis of NS accounted for 3\% (22/820) of confirmed CSF microbial diagnoses however the HIV status was not stated in that study ${ }^{62}$. In Mozambique in a series of 21 patients presenting with latent syphilis and HIV co-infection 4 cases of asymptomatic NS were reported however none had a positive CSF rapid plasma regain test on $\mathrm{LP}^{101}$. In Nigeria in a series of 31 patients with syphilis and HIV co-infection no case of NS was reported ${ }^{102}$. Syphilis has been reported in association with myelopathy in HIV in Africa ${ }^{103,104}$. The overall risk of NS developing in untreated syphilis/HIV is known to be increased, $23 \%$ versus $10 \%$ in-untreated syphilis/non-HIV suggesting a 2-3 fold increased risk of NS in $\mathrm{HIV}^{99,105}$.

Clinically the natural history of NS may also be altered in HIV disease with an increased rate of early neurological involvement including meningitis, meningovascular and ophthalmic syphilis whereas tabes dorsalis and gener- 
alised paralysis of the insane (GPI) remain as the classical late manifestations. The diagnosis of NS relies on a high index of clinical suspicion combined with characteristic CSF findings and serological evidence of syphilis in blood and CSF. Typical CSF findings include $>20$ lymphocytes/ $\mathrm{mm}^{3}$, elevated protein and normal or reduced glucose. Serological screening tests include Venereal Disease Research Test (VDRL) and rapid plasma regain tests (RPR) and confirmation tests include Treponema pallidum haemagglutination assay (TPHA) and flocculation Treponema antibody absorption (FTA-ABS). The gold standard for diagnosing NS is a reactive CSF on VDRL testing, however CSF VDRL is notably unreactive in $30-70 \%$ of cases of $\mathrm{NS}^{32}$. The Treponema antibody tests TPHA/FTA are more sensitive but less specific because of cross-reaction with possible leaked blood in CSF (antibody). While a negative screening test makes NS less likely ${ }^{99}$ notably they can also be negative in the presence of NS/HIV. Neuroimaging may show meningeal enhancement, infarction or gammas.

Treatment for NS is recommended in HIV infected patients if the serum/CSF screening tests are positive and in the case of negative CSF VDRL but with abnormal CSF findings consistent with NS. First line treatment is with soluble penicillin or ceftriaxone for 14-21 days duration, however treatment may not be effective in as many as $23-60 \%$ of $\mathrm{HIV} / \mathrm{NS}$ infected patients. In these a longer course of treatment for 3-4 weeks may necessary or doxycycline $200 \mathrm{mgs}$ twice daily where a hospital stay or outpatient antibiotics are not possible ${ }^{99}$. Relapse of infection is also more likely in HIV ${ }^{32,99}$, and a follow up CSF examination should be done every 6 months for up to 2 years. Retreatment may be necessary if clinically disease persists or recurs or when there are persistent lymphocytes in CSF.

\section{Lymphoma}

The overall frequency of malignancies in HIV deaths undergoing autopsy in Africa ranges between 11-16\% with the most common being Kaposi sarcoma 8-16\% and systemic lymphoma $1-3 \%{ }^{6}$. A recent autopsy study in SA on 39 adults, $(64 \%$ on ART) reported a higher overall frequency of malignancy 23\%, (Kaposi sarcoma 15\%, and systemic lymphomas $8 \%)^{4}$. The reported frequency of primary CNS lymphoma (PCNSL) in clinical and postmortem series in Africa is either very low (0-1.3\%) or absent $t^{6,8,11,24,106}$. This is in contrast to HICs where higher rates are reported ${ }^{107}$. PCNSL typically presents in advanced HIV disease as nonspecific headache lasting weeks coupled with neurological features of a focal brain lesion. The diagnosis is based on the clinical presentation, coupled with the finding of a homogenous, solid, focal or multifocal hypodense enhancing periventricular lesion on CT with no or relatively little surrounding edema, CD4 $<50$ cells $/ \mathrm{mm}^{3}$, evidence of positive Epstein Barr virus in CSF and no response to TB/Toxo treatment. Management of focal brain lesions in HIV in Africa is mostly empirical treating first for toxoplasmosis or tuberculosis or both depending on whichever is most endemic in that region. The prognosis for CNS lymphoma in HIV is particularly poor in Africa ${ }^{4,106}$.

\section{Stroke}

The frequency of strokes is increased in HIV infection in Africa ${ }^{108,109}$. A community based stroke study in Tanzania in 2013 showed an increased frequency of HIV infection in new onset strokes, $25 \%$ versus $6.6 \%$ in controls, odds ratio (OR) 5.6 $6^{110}$. A similar trend, (OR) 2.1 was reported in $\mathrm{SA}^{111}$. Notably some earlier studies in Africa showed no such association ${ }^{112-114}$. Possible reasons included the exclusion of patients with an AIDS defining illness, a group that is more likely to develop stroke. In SA in a hospital-based study involving 506 adult HIV patients, stroke was present in $2 \%, 80 \%$ of which occurred in association with CD 4 counts $<200 / \mathrm{mm}^{3}$. The majority of strokes two thirds, occurred without any known underlying cause while less than one third occurred in association with meningitis ${ }^{24}$. These findings agree with reported increased TIA/stroke prevalence in HIV disease, its more frequent occurrence in WHO HIV stages III/IV and also occurring at a younger age $\mathrm{e}^{115}$.

The main mechanisms of stroke in HIV infection are cerebral ischaemia/infarction $80-96 \%$ and intracerebral haemorrhage 4-20\%. In a large stroke study in SA, a HIV infected subgroup of $6.1 \%(67 / 1087)$ was identified, of whom cerebral infarction occurred in $96 \%$ and intracerebral haemorrhage occurred in $4 \%{ }^{116}$. In ischaemic stroke/ $\mathrm{HIV}$ in Africa the main identified causes were infectious meningitides/vasculitis $28 \%$, coagulopathy $19 \%$, cardio embolism 14\%, HIV associated vasculopathy $20 \%$ and multiple causes $11 \%{ }^{113,115}$. Large vessel site in cryptogenic stroke was identified in one study in SA suggesting 
the presence of a co-existent prothrombotic state as a risk factor ${ }^{114}$. Concurrent systemic infection, the first 6 months of ART treatment and IRIS may be independent risk factors for stroke in Africa ${ }^{116,117}$. The natural history of stroke/HIV appears unchanged from that of stroke/ non-HIV stroke but stroke inadvanced HIV disease has a poor prognosis. While primary prevention of stroke is the main aim, secondary intervention measures include ART, strict control of BP and the use of antiplatelet drugs and statins ${ }^{108,118}$.

\section{Seizures}

New onset seizures occur in up to $11 \%$ of HIV infected persons ${ }^{14,40,119-126}$. They occur at all stages of HIV infection but mainly at WHO stages III/IV ${ }^{119}$. The main causes are opportunistic processes, mostly infections including: meningitis mainly cryptococcus, viral encephalitis, toxoplasmosis and less commonly, antiretroviral medications and hyponatraemia ${ }^{119,123}$. In HIV in Africa up to $75 \%$ of seizures occur in the context of known treated or untreated HIV infection whilst in $25 \%$ the seizures are the presenting complaint of previously undiagnosed HIV infection ${ }^{120}$. The seizure type identified most commonly in Africa is generalized tonic clonic with multiple or recurrent seizures occurring in $>50 \%$ of cases and status epilepticus occurring in $15 \%{ }^{119}$. Investigations in Africa should include laboratory screening of blood and CSF for evidence of treatable pathogens in particular for cryptococcus, toxoplasmosis, TB and NS and also neuroimaging if available. Clinical or radiological evidence of a focal cause may be present in up to two thirds of seizure patients ${ }^{119}$. Management includes treating the underlying cause and the use of antiepileptic drugs that do not interact with ART. Mortality is significantly increased in seizures in HIV and a mortality rate of $37 \%$ was recently reported in a cohort of 81 seizure patients from Zambia with a median follow up period of 306 days ${ }^{119}$. The main risk factor for death as an outcome in that study was late WHO HIV stage at initial clinical presentation.

\section{Direct HIV infection}

The main NDs occurring as a result of direct HIV infection are HIV-associated neurocognitive dysfunction (HAND), neuropathy and myelopathy. These disorders are reported in clinical studies across Africa ${ }^{24,28}$, their presence and frequency largely considered to be a function of the clinical stage of the patient at presentation and degree of underlying immunosuppression.

\section{HIV associated neurocognitive disorder (HAND)}

$\mathrm{HIV}$ is a major cause of neurocognitive impairment. The term neurocognitive impairment was redefined in 2007 by the American Academy of Neurology as HIV associated neurocognitive disorders (HAND) which includes the following: asymptomatic neurocognitive impairment, mild neurocognitive disorder and HIV-associated dementia (HAD). Collectively they can also be grouped as minor cognitive and motor disorders and HIV-associated dementia (HAD) ${ }^{127}$. HAND in SSA is mostly measured by the International HIV Dementia Scale (IHDS) which measures motor speed (timed finger tapping), psychomotor speed and learning (timed alternating sequence test), registration (naming 4 items) and memory (recall of 4 items at 2 minutes) and scored out of 16, a score of 10 or less being significant in Africa. The IHDS has a reported low sensitivity $45-69 \%$ and specificity $74-80 \%$ in HIV in Africa ${ }^{127-129}$ possibly because of comorbidity and advanced disease. However, a recent cohort study involving 266 adults on ART in Zambia with a prevalence of HAND of $34.6 \%$ has established its validity using a comprehensive battery of neuropsychological tests ${ }^{130}$. Also important normative baseline data is provided in a recent multi country study including some from Africa ${ }^{131}$. There is a wide variation in the reported frequency of HAND in Africa as reported from individual countries ${ }^{132,133}$ : SA 18$80 \%{ }^{134}$, Malawi $14 \%{ }^{135}$, Zambia $22 \%{ }^{136}$, Uganda $64.4 \%{ }^{137}$, and Cameroon $85 \%{ }^{138}$.

In one study in West Africa involving a HIV-2 infected cohort no significant increase in HAND was found compared to HIV-2 negative controls ${ }^{45}$. A high frequency of HAD $54 \%$, was reported in a cohort of patients presenting with advanced HIV disease $\mathrm{e}^{28}$ in an early study in Tanzania. A high frequency of frontal lobe release signs: snout reflex $87 \%$ and palmomental reflex $69 \%$ has also been reported in advanced HIV disease in Africa ${ }^{28,139}$. In Uganda a high rate of HAND 89\%, was reported in association with HIV subtype Clade D, in contrast to $24 \%$ in Clade $\mathrm{A}^{140,141}$. However a subsequent study there showed no association of HAND (41\%) with HIV subtype ${ }^{142,143}$. HIV subtype Clade $\mathrm{C}$ predominates in SA where a frequency of HAND $38 \%$ was reported ${ }^{24}$. In a recent review of HAND, the reported mean prevalence in Africa in the pre-ART era was 42.3\% (15.6-80\%) and in Uganda 46.5\% (30.6-62.4\% $)^{127}$. ART improves HAND with reported rates six months post ART significantly lower in Uganda $28.5 \%$ and in Africa $30.4 \%$ with a $63 \%$ improvement reported in similar subjects in Uganda ${ }^{127}$. However 
in one study in Uganda while ART use overall was associated with improvements in cognitive functioning among $\mathrm{HIV}+$ persons, these were no greater than those seen among HIV+ persons who did not initiate ART possibly suggesting patient test learning bias ${ }^{144}$.

Noticeably any improvement in the rate of HAND peaks and plateaus after nine months ART with persistence of the milder asymptomatic or dysfunction forms ${ }^{129,145,146}$. Qualitatively there are also differences with pre-ART HAND characterized by psychomotor slowing: inattention, slow thinking, forgetfulness, unsteady gait, tremor and social withdrawal, whilst post ART HAND is characterized by more cortical involvement, with impaired learning ability, memory executive function and extrapyramidal motor features. There is little evidence of clinically significant chronic neurological dysfunction in chronic HIV-2 infection in West Africa ${ }^{140,146}$. HAND is a process caused by the direct effects of HIV virus infection which are independent of opportunistic processes. While some studies in SSA report a number of risk factors for HAND in particular advanced age, advanced WHO clinical stage, low CD 4 counts, and anaemia ${ }^{147,148}$, other studies report no such association or a less strong association with HIV stage $^{127,129}$. An independent association with cardiovascular disease and inflammation has also been reported ${ }^{146}$. While the burden of HAND decreases significantly post ART, it is important to remember that despite ART one third to one half of HAND affected persons in Africa will remain affected with persistence of the milder forms. Strategies aimed at decreasing the burden of HAND include starting combined ART as early as possible in HIV infection, the development and use of ART regimes with better CNS penetration and effectiveness for the control of replication and elimination of HIV from its main CNS reservoirs in microglia and macrophages. Other strategies in HICs including the use of adjunctive therapies including anti-inflammatory measures such as low dose methotrexate, statins and antiepileptic medication have either proved ineffective or not significant. At present the strategy of choice available in Africa is starting ART as early as possible in HIV infection and decreasing or treating known risk cardiovascular risk factors ${ }^{145,146}$.

\section{Distal Sensory Neuropathy (DSN)}

Neuropathies occur at all stages of HIV infection. The main neuropathies are distal sensory neuropathy (DSN), inflammatory neuropathies, radiculopathies and mononeuropathies. DSN is the most common occurring mostly during the symptomatic stage of HIV disease (WHO stages $3 \& 4$ ) and was reported early on in the HIV epidemic in Africa ${ }^{28,36}$. The main symptoms of DSN are a burning, stabbing pain and paresthesia or numbness in the soles of the feet ascending symmetrically and less commonly involving the hands. Notably the pain or discomfort is most apparent on touching the soles or palms. Sensory symptoms are reported to be present in about $75 \%(50-90 \%)$ of DSN patients in Africa ${ }^{148}$. Signs of DSN include reduced or absent ankle reflexes and/or impaired light touch and/or impaired vibration and joint position sense.

The prevalence of DSN depends on the criteria used to define it and include any two of three signs with or without symptoms (symptomatic and asymptomatic) or any one sign with symptoms (symptomatic) $)^{149,150}$. More recently a clinical tool using 4 items: pain, numbness, ankle reflexes and vibration has been validated for use in Afri$\mathrm{Ca}^{151}$. The pathophysiology of DSN is a distal axonal neuropathy secondary to activated dorsal root inflammation most probably due to viral proteins, $\mathrm{gp}^{120}$. The estimated pooled frequency of DSN in the pre ART era in Africa was $27 \%(11-37 \%)^{149,152,153}$. A much lower frequency of $3.9 \%$ was reported in a single large study from SA ${ }^{154}$. The worldwide prevalence during the same period ranged between $20-57 \%{ }^{149}$. A frequency of $50 \%$ was reported in HIV2 in one study in West Africa using just one sign+/symptoms ${ }^{45}$. In the post ART era in Africa there was a significant increase in frequency of DSN with pooled frequencies of DSN of $52 \%(36-60 \%)^{149,150,152,153,155-159}$. This increase was attributed to the widespread use of dideoxynucleoside reverse transcriptase inhibitors as a first line ART, in particular stavudine with the neuropathy typically beginning 5-6 months post starting ART $^{153,158,160}$. In a recent study from SA involving a cohort of patients 2 years after starting ART ( $60 \%$ on stavudine) a slight increase in the frequency of symptomatic DSN from baseline $16 \%$ to $18 \%$ was reported with a $50 \%$ decrease in significant pain ${ }^{161}$. The rate of symptomatic DSN decreased from 22 to $17 \%$ in another study in SA involving $2^{\text {nd }}$ line ART patients with an almost 2 year follow up period, notably the rate of asymptomatic DSN in that study increased from $21 \%$ to $29 \%{ }^{162}$. Some studies from West Africa report a decrease in the frequency of DSN at three months post starting ART which may have been too early to observe 
this side effect of stavudine ${ }^{163,164}$. The main risk factors for DSN are advanced HIV disease, lower CD4 count, high viral load, advancing age, and a history of prior TB or alcohol intake ${ }^{149,153,162}$. Up to a quarter of ART treated HIV persons in Africa may be affected with symptomatic DSN for life ${ }^{162-164}$.

The management of DSN involves pain control with available neuropathic specific medications including amitriptyline, gabapentin, pregabalin and lamotrigine and the use of opioids only if necessary, however most patients tolerate their symptoms without medications. Strategies aimed at decreasing the burden of DSN in Africa include an early test and treat HIV policy, avoiding dideoxynucleoside reverse transcriptase inhibitors, an increased awareness of other possible concurrent causes of neuropathy i.e. alcohol, diabetes mellitus and pyridoxine deficiency secondary to isoniazid.

\section{Mononeuropathies}

Mononeuropathies are common in HIV infection in Africa $^{149}$. The most common are facial nerve palsy or Bell's palsy and neuropathy complicating reactivation of herpes zoster in dorsal root ganglia ${ }^{165-168}$. Facial nerve palsy occurs most frequently at or around the time of seroconversion after primary infection and during the asymptomatic phase of HIV infection. During the early epidemic in Africa $>50 \%$ of patients presenting with facial nerve palsy tested seropositive for HIV ${ }^{169}$. Facial nerve palsy/HIV is characteristically unilateral but may infrequently be bilateral or occur as part of a generalized acute inflammatory demyelinating neuropathy. Investigation, management and response to treatment are similar to facial nerve palsy/non-HIV. Herpes zoster reactivation is one of the earliest and most recognizable clinical presentations of HIV with its characteristic locally aggressive multi dermatomal involvement, involvement of atypical sites including face, cranium and sacrum and subsequent marked scarring. It affects $5-10 \%$ of $\mathrm{HIV}$ infected patients in Africa with the mean survival time estimated in the pre-ART era to be around 42 months ${ }^{166,168}$. It most commonly involves the thoracic and trigeminal nerves. Complications include dissemination, myelitis and pain, post herpetic neuralgia. Acute management is with acyclovir and pain control as for non-HIV. Other neuropathies that occur in HIV include other cranial nerve palsies, optic neuritis and mononeuropathies ${ }^{149,170}$. These are mostly either au- toimmune based or secondary to opportunistic processes e.g. TB/lymphoma resulting in entrapment/infiltration in advanced disease.

\section{Myelopathy}

Paraplegia is common in Africa and the main causes of non-traumatic myelopathy in adults are $\mathrm{TB}$, transverse myelitis and metastatic disease. Myelopathy also occurs in HIV infection, the main causes being opportunistic infections and tumours and vacuolar myelopathy (VM), the latter occurring as a result of direct HIV infection of the spinal cord. In a series of 97 patients from SA presenting with non-traumatic myelopathy a total of $50 \%$ were found to be HIV positive in which infections accounted for $72 \%$ of the causes ${ }^{171}$. These infections included TB $50 \%$, VM 16\%, varicella zoster (VZ) 4\% and cytomegalovirus infection (CMV) $1 \%$. Other causes included demyelinating disorders, acute demyelinating encephalomyelitis (ADEM) $8 \%$, neuromyelitis optica 4\%, neoplasms $12 \%$ and B12 deficiency $2 \%{ }^{171}$. In another large series of HIV myelopathies from SA, TB accounted for 68\% (84/123) of the cases of CSF culture or biopsy proven causes including all the cases of spondylitis (Potts Disease) and $40 \%$ of the myeloradiculopathies ${ }^{172}$. Syphilis and human T-cell lymphotropic virus type 1 have also been reported in association with myelopathy and HIV in Africa with alterations of their natural history characterized by a shortening of time to clinical onset ${ }^{103,104}$.

\section{Vacuolar myelopathy}

VM occurs as a consequence of direct HIV infection of spinal cord and immunosuppression and in its severe form it is characterized by a slowly progressive painless spastic paraparesis with sensory ataxia and bladder involvement occurring mainly in association with symptomatic HIV disease. While VM has been reported in myelopathy/ HIV series in Africa with varying frequency from 1.4 to $16 \%{ }^{103,171,173}$ there are few reports of VM in symptomatic HIV disease. Notably VM was reported to be present in $2 \%$ of patients in a large series of 507 symptomatic HIV infected patients in $\mathrm{SA}^{24}$. This contrasts with higher rates of $5-10 \%$ reported in HIV in HICs. However in an early study in Africa it was reported to be present in $>20 \%$ of a series of advanced AIDS patients presenting mainly as a subclinical finding characterized by isolated hyperreflexia at the knees and extensor plantar reflexes ${ }^{28}$. Notably myelopathy was not reported in a study involving a cohort 
of HIV-2 patients in West Africa ${ }^{139}$. The main pathology in VM is vacuolation of the white matter in the thoracic/cervical spinal cord present in $20-55 \%$ patients. The main risk factor for VM is advanced immunosuppression. Management is aimed at excluding a treatable underlying cause of myelopathy and symptomatic treatment. The use of ARTs appears not to be effective in terms of decreasing the existing burden of VM and strategies aimed at preventing it include earlier ART intervention before it develops.

\section{Radiculopathy}

Radiculopathy in HIV is uncommon and is mostly confined to the lumbosacral nerve roots with patients typically presenting over days or less frequently weeks with a rapid onset progressive flaccid paraplegia with areflexia and urinary incontinence without upper limb involvement. The main causes in HIV in SSA are tuberculosis and $\mathrm{CMV}^{149,166}$. Radiculopathy caused by TB arises either direct as a granulomatous arachnoiditis involving the cauda equina or from Potts disease of the lumbar spine. Investigations for TB include CSF examination and spinal and chest X-rays. CSF examination in spinal TB shows elevated cells, mostly polymorphs early in the course of the disease and later lymphocytes, coupled with an elevated protein and low glucose but may be normal with a typically negative TB culture and normal chest $\mathrm{x}$-ray. A recent report from Tanzania describes a case of tuberculous spondylitis/HIV diagnosed through Xpert assay in urine ${ }^{174}$. Cytomegalovirus infection typically occurs in persons with advanced HIV disease ( $<50$ CD4 cells/ $\mathrm{mm}^{3}$ ) and results in a rapidly progressive and painful flaccid paraplegia with bladder involvement. CSF typically shows increased white blood cells mainly polymorphs, elevated protein and low glucose but may be normal. PCR is highly sensitive and specific with $97 \%$ negative predictive value ${ }^{149}$. There may also be clinical evidence of CMV infection elsewhere e.g. retinitis. Treatment is empirical with ganciclovir iv for 14 days coupled with early ART. Uncommon causes of radiculopathy include an early manifestation of HIV virus infection, CD8 infiltrative lymphocytosis syndrome, Epstein-Barr virus related metastatic lymphoma,herpes simplex virus type 2 and syphilis ${ }^{149}$.

\section{Inflammatory disorders}

Autoimmune mediated inflammatory disorders are in- creased in HIV but are relatively uncommon ${ }^{175}$. These include acute inflammatory demyelinating polyneuropathy ADEM, myasthenia gravis, polyneuropathies and polymyositis. ADEM/HIV affects both children and adults and its onset in HIV is characteristically associated HIV seroconversion with a relatively intact immunity. However in a recent series of 7 adult patients from SA the mean CD4 count was 368 (range149-533) suggesting its onset can occur with more advanced immune dysregulation ${ }^{176}$. Atypical clinical features in that series included frequent optic neuritis, mass lesions mimicking opportunistic processes and a more aggressive sometimes relapsing course though remaining responsive to immunomodulation. Myasthenia gravis is associated with HIV and while the overall incidence rate of $\mathrm{MG}$ in $\mathrm{SA}^{177}$ is similar to that reported in HICs there are no published reports of MG/ HIV from Africa. MG/HIV typically occurs as part of post ART immune restoration or IRIS and responds to standard MG treatment ${ }^{178}$.

The main immune mediated polyneuropathies in HIV are acute inflammatory demyelinating polyneuropathy (AIDP or Guillain-Barre syndrome) and chronic inflammatory polyneuropathy (CIDP). These are uncommon NDs and an estimated frequency of AIDP has been reported as $0.8 / 100,000$ in Tanzania ${ }^{179}$. A strong association of AIDP and HIV was reported early in the epidemic in Africa in consecutive series of AIDP patients with HIV seropositive rates ranging from $31-84 \%{ }^{179-181}$. The reported frequency of CIDP in HICs ranges from 1 to $7.7 / 100,000$. There is less information on its frequency in Africa but it is described there in association with $\mathrm{HIV}^{36,181,182}$. CIDP differs clinically from AIDP in that its onset is slower, over 8 weeks, progression and remission can occur, and it is usually steroid sensitive. The clinical findings in both are largely similar to those in non-HIV. AIDP typically present with symmetrical limb weakness, areflexia and mild or absent sensory symptoms or signs whereas CIDP presents with symmetrical weakness both proximal and distal, areflexia coupled with sensory symptoms and signs. AIDP/HIV tends to occur in association with relatively intact immunity or at seroconversion whereas CIDP tends to occur in association with moderately advanced HIV disease with lower CD4 counts but it can also occur with higher CD4 counts. A progressive clinical course in CIDP/HIV rather than relapsing as occurs in CIDP/non-HIV was reported recently in SA ${ }^{183}$ 
An association of CIDP with IRIS post ART is also described. Laboratory investigations including elevated CSF protein are similar but a CSF pleocytosis $\left(<50\right.$ cells $\left./ \mathrm{mm}^{3}\right)$ is more likelyin HIV infection. The differential diagnosis for CIDP includes CMV/TB/lymphoma related radiculopathies and deficiency states including B6 (pyridoxine) and B12 deficiency. Management is the same as for AIDP/CIDP/non-HIV including immunomodulation in AIDP and steroids in CIDP. The response to immunomodulation treatment and outcome are reported to be largely similar in both HIV and non-HIV groups ${ }^{149,180}$ a higher mortality rate was reported in AIDP/HIV in one study in Tanzania ${ }^{178}$.

Muscle disease is increased in HIV infection and is of two main types, myopathy and polymyositis. Myopathy is the most common type and is characterized by painless, generalized muscle weakness and wasting and typically occurred in the majority of patients with advanced HIV infection in the early epidemic in Africa when AIDS was named slim disease184. Polymyositis/dermatomyositis in HIV have both been described in Africa ${ }^{185,186}$. In a series of polymyositis reported from SA involving 14 ART naïve adult patients, all of whom were female, the mean CD4 was $261 / \mathrm{mm}^{3}$ (range10-820); they had significantly lower creatinine kinase levels than polymyositis/nonHIV controls and responded well to steroids ${ }^{185}$.

\section{Discussion}

\section{Early HIV diagnosis and ART}

Historically in Africa the WHO recommended level of CD4 counts $/ \mathrm{mm}^{3}$ for starting ART has gradually increased from 200 cells in 2006 to 350 in 2009 and 500 cells in 2013. A significant decline in the incidence of the main CNS/OIs was recently reported in a paper from SA involving a 4-year study period 2009-12. During that study the incidence of CM decreased by $23 \%$, TBM by $40 \%$ and ABM by $41 \%{ }^{60}$. This was attributed to expansion of the national antiretroviral treatment program and to TB program strengthening and pneumococcal vaccination. In Sept 2015 WHO announced a new "Test and Treat" policy globally for persons/patients with HIV regardless of CD4 level. This new policy was based on studies involving the use of early or immediate ART in HIV positive adults and isoniazid chemoprophylaxis which resulted in significantly improved outcomes ${ }^{187,188}$. A major benefit of adopting this new test and treat policy will be the reduction in the burden of NDs in HIV in Africa.

\section{Cryptococcal Meningitis (CM)}

The estimated global prevalence of asymptomatic cryptococcal antigenaemia in persons with CD $4<100$ cells/ $\mathrm{mm}^{3}$ is $6.0 \%(\mathrm{r} 2-15 \%)$ with even higher rates, $16 \%$ reported from Africa46. CM can be prevented by identifying subclinical infection by screening for $\mathrm{CrAg}$ in serum at the same time as when screening for HIV on entry into ART programs, a time when the majority of HIV diagnoses are made ${ }^{189}$. It can be detected weeks to months before the onset of meningitis. CrAg is highly sensitive and specific with 100\% negative predictive value and costs less than $4 \$ /$ test $^{69,70}$. Targeted screening and preemptive therapy for $\mathrm{CrAg}$ positives in persons with CD4 <100 cells $/ \mathrm{mm}^{3}$ and chemoprophylaxis with fluconazole is now recommended for Africa ${ }^{46}$. Newer, cheaper, recently approved, rapid, easy to use, point of care diagnostics including lateral flow immunoassay may prove particularly useful for establishing the diagnosis of CM in Africa ${ }^{190,191}$. The optimum management for CM is with amphotericin-based treatment however a major limitation is expense with standard amphotericin costing \$8-10 a day and liposomal Amp B $\$ 16 /$ a day in contrast to $\$ 0.15$ per single $200 \mathrm{mg}$ fluconazole tablet. Research into the efficacy of shorter Amp B based treatment courses combined with high dose fluconazole is already underway in Africa ${ }^{192}$. A recent study in Tanzania and Zambia incorporating CM screening in combination with a short period of community based support reduced mortality by $28 \%{ }^{193}$.

Intervention strategies for CM in Africa include 1) HIV "Test and Treat" policy, 2) screening for cryptococcus during HIV screening programs and chemoprophylaxis if CrAg or LFA positive and CD4 counts are $<100 / \mathrm{mm}^{3}$, 3) improved point of care diagnosis with a lower threshold for both diagnostic and therapeutic LPs, 4) the use of fungicidal Amp B based treatment regimens, 5) deferred starting ART for 4-6 weeks after starting CM treatment and 6) community based support.

\section{Tuberculous Meningitis (TBM)}

TB is the leading cause of death in HIV in Africa. The adoption of the recently introduced "Test and Treat" ART policy will serve to decrease the huge burden and mortality of TB in HIV in Africa and in turn TBM ${ }^{60}$. This 
is supported by the use of intermittent 6 month isoniazid prophylaxis therapy (IPT) which has shown in Africa to reduce incidence of TB by $33 \%$ and by $64 \%$ if tuberculin skin positive and mortality by almost $70 \%$ in one study but for sustained benefit the strategy needs to be repeated intermittently probably every 2 years ${ }^{14}$. In 2010 WHO introduced a "Three I's" strategy of 1) TB intensive case finding 2) isoniazid prophylaxis and 3) infection control together with intensified ART. However its implementation has been variable across Africa ${ }^{194}$. An increased effort must now be made to support the implementation of the "Three I's" strategy together with the new "Test and Treat" ART policy across Africa. The possible benefit of using combined preventative therapy of isoniazid for TB together with co-trimoxazole for pneumocystis carinii in a fixed dose single tablet formulation to facilitate compliance has also been proposed ${ }^{195}$. The clinical recognition and confirmatory diagnosis of TBM is notoriously difficult particularly in Africa and is traditionally based on clinical, laboratory and radiological findings with poor sensitivities $^{80}$. Any new strategy targeted at improving outcome must involve having a lower clinical threshold for carrying out diagnostic LP in suspected cases coupled with the use of the newer rapid POC diagnostics on CSF because of their higher sensitivities $60-80 \%$ and specificities 95\%. These POC tests include Xpert LAM (LFA) and LAM (ELISA). The next generation assay Xpert U1tra appears to be significantly more sensitive than Xpert in diagnosing TBM. ${ }^{77,81,83}$. Xpert has the additional benefit of MDR-TB screening and recommended for Africa by WHO the major limitation being expense. In TBM the optimum time for starting ART prophylaxis is 4-6 weeks after initiating TB treatment, in contrast to 2 weeks in systemic $\mathrm{TB} / \mathrm{HIV}^{17}$. BCG is highly protective against TBM in children however its protective role in TBM/HIV is uncertain ${ }^{14}$. Research into intensified anti-tuberculous therapy using agents with better CNS penetration is ongoing.

Intervention strategies for TBM/HIV in Africa include 1) HIV Test and Treat" policy, 2) intermittent isoniazid chemoprophylaxis to decrease the overall TB/TBM burden, 3) improved TBM clinical case finding and diagnosis using Xpert and best management, 4) deferred starting ART initiation for 4-6 weeks after starting TBM treatment and 5) community-based support.

\section{Other Opportunistic Infections}

The other main CNS/OIs are TE, ABM and syphilis. In TE the diagnosis and treatment are often empirical in persons presenting with NDs suggestive of focal brain lesions coupled with a positive toxoplasmosis serology. The treatment of TE has been already outlined and steroids are only indicated where there is substantial mass effect and should be discontinued early.

Intervention strategies for TE in Africa include 1) HIV Test and Treat" policy 2) serological screening for toxoplasmosis IgG antibodies especially in low prevalence areas with primary chemoprophylaxis with trimethoprim-sulphamethoxazole in IgG positive HIV infected persons until CD 4 is $>200 / \mathrm{mm}^{3}$ for at least 3 months 32 , 3) early clinical diagnosis and 4) ART initiation 2 weeks after the start of TE treatment.

In $\mathrm{ABM}$ vaccination offers an important strategy in prevention. The polysaccharide pneumococcal vaccine showed no benefit when used in Africa and is not recommended there. However, in a recent study involving Malawian adults, $88 \%$ of whom were living with HIV and had recovered from a pneumococcal disease, the use of a pneumococcal conjugate vaccine (PCV-7) decreased recurrent episodes of pneumococcal invasive disease by $74 \%$. The use of a combination of polysaccharide pneumococcal vaccine and PCV7 suggests a potentially strong benefit as a method of primary prevention of bacteraemia, pneumonia and meningitis in HIV infection in Afri$\mathrm{ca}^{14,18,60}$. Similarly the introduction in 2009 in West Africa of a new meningococcal conjugate serogroup A vaccine has decreased epidemics and outbreaks there by $80-85 \%$ suggesting a preventative role in $\mathrm{HIV}^{14}$.

Intervention strategies aimed at decreasing the burden and mortality of $\mathrm{ABM} / \mathrm{HIV}$ include 1) vaccination 2) early antibiotics based on clinical suspicion 3) better POC diagnostic tests and 4) informed antibiotic choice ${ }^{18,60}$. In cases of suspected neurosyphilis a low threshold for serological and CSF screening is recommended ${ }^{99,105}$. Other opportunistic processes reported in HIV in Africa including PML, primary CNS lymphoma and MDR TB are presently non-curable ${ }^{107}$.

\section{Direct HIV infection}

The main intervention strategy aimed at decreasing the 
burden of HAND, DSN and VM in Africa is the recently introduced WHO HIV "Test and Treat" policy in order to prevent or decrease their occurrence in the first place. It is likely that this group of disorders will be one of the major beneficiaries of the new policy to "Test and Treat" with early or immediate ART ${ }^{187,188}$. The availability and selection of ART drugs with better CNS penetration remains a critical issue for the future but not just in Africa. There is also a need for longitudinal cohort studies for a better understanding of the long term social, cultural, economic and medical impact of HAND in Africa with an ageing HIV infected population.

\section{Conclusion}

This paper has reviewed the burden, clinical features, causes and outcome of the main NDs in HIV in Africa. Opportunistic infections, in particular cryptococcus and TB have been identified as major causes of mortality and direct HIV infection as the main cause of morbidity. The high rates of mortality and morbidity are in turn related to late clinical presentation, advanced immunosuppression and difficulties in recognition, diagnoses and management. It is imperative that the intervention strategies presented in this paper be adopted.

\section{Acknowledgements}

The author wishes to thank Marieke Dekker, Ines Said, Sven Hideracker, Neema Minja, Mathew Ruback, Susan Tyzack, Patrick Howlett, Fiona Cresswell, Joe Jarvis and David Lawrence for reading the manuscript.

\section{Funding}

The author has no support or funding to report.

\section{Competing interests}

The author has declared that no competing interests exist.

\section{Abbreviations}

HIV, human immunodeficiency virus; NDs, neurological disorders; CNS, central nervous system; OIs, opportunistic infections; CFR, case fatality rates; HICs, high income countries; TB, tuberculosis; CM, cryptococcal meningitis; TBM, tuberculous meningitis; ABM, acute bacterial meningitis; TE, toxoplasma encephalitis; IRIS, immune reconstitution inflammatory syndrome; NS, neurosyphilis; PCNSL, primary CNS lymphoma; HAND, HIV associated neurocognitive dysfunction; OIs, opportunistic infections; DSN, distal sensory neuropathy; VM, vacuolar myelopathy; PML, progressive multifocal leukodystrophy; ART, antiretroviral therapy; CSF, cerebrospinal fluid; LP, lumbar puncture; CrAg cryptococcal antigen; LFA, lateral flow assay; POC, point of care; LAM, lipoarabinomannan; ELISA, enzyme-linked immunosorbent assay; CT, computerized tomography; MR, mortality rate; MDR, multidrug resistant; PM, pneumococcal meningitis; GCS, Glasgow Coma Scale; VDRL, Venereal Disease Research Test; RPR, rapid plasma reagin tests; TPHA, Treponema pallidum haemagglutination assay; FTA-ABS, flocculation Treponema antibody absorption; OR, odds ratio; SSA, Sub-Saharan Africa; SA, South Africa; WHO, World Health Organization; DSN, distal sensory neuropathy; AIDP, acute inflammatory demyelinating polyneuropathy; CIDP, chronic inflammatory demyelinating polyneuropathy; CMV, cytomegalovirus; ADEM, acute demyelinating encephalomyelitis; IPT, isoniazid prophylactic therapy; PCV-7, pneumococcal conjugate vaccine; Xpert, Gene Xpert TB/RIF;

\section{References}

1. Lucas S, Nelson AM. HIV and the spectrum of human disease. J Pathol. 2015 Jan;235(2):229-41

2. Bates M, Mudenda V, Shibemba A, Kaluwaji J, Tembo J, Kabwe M, et al. Burden of tuberculosis at post mortem in inpatients at a tertiary referral centre in sub-Saharan Africa: A prospective descriptive autopsy study. Lancet Infect Dis. 2015;15: 544-551. doi:10.1016/S14733099(15)70058-7

3. Bates M, Mudenda V, Mwaba P, Zumla A, M. B, V. M, et al. Deaths due to respiratory tract infections in africa: $A$ review of autopsy studies. Curr Opin Pulm Med. 2013;19: 229-237. doi:10.1097/MCP.0b013e32835f4fe4

4. Wong EB, Omar T, Setlhako GJ, Osih R, Feldman C, Murdoch DM, et al. Causes of Death on Antiretroviral Therapy: A Post-Mortem Study from South Africa. PLoS One. 2012;7. doi:10.1371/journal.pone.0047542

5. Cox JA, Lukande RL, Nelson AM, Mayanja-Kizza H, Colebunders R, van Marck E, et al. An autopsy study describing causes of death and comparing clinico-pathological findings among hospitalized patients in kampala, uganda. PLoS One. 2012;7. doi:10.1371/journal. pone.0033685

6. Cox JA, Lukande RL, Lucas S, Nelson AM, Van Marck E, Colebunders R. Autopsy causes of death in HIV-positive individuals in sub-Saharan Africa and correlation 
with clinical diagnoses. AIDS Reviews. 2010. pp. 183-194. 7. Ansari NA, Kombe AH, Kenyon TA, Hone NM, Tappero JW, Nyirenda ST, et al. Pathology and causes of death in a group of 128 predominantly HIV-positive patients in Botswana, 1997-1998. Int J Tuberc Lung Dis. 2002;6: 55- PubMed ;63.

8. Lucas SB, Hounnou A, Peacock C, Beaumel A, Djomand G, N-Gbichi J-M, et al. The mortality and pathology of HIV infection in a West African city. AIDS. 1993;7: 1569- PubMed ;1579. doi:10.1097/00002030199312000-00005

9. Karat AS, Omar T, Von Gottberg A, Tlali M, Chihota VN, Churchyard GJ, et al. Autopsy prevalence of tuberculosis and other treatable infections among adults with advanced HIV presenting to out-patient care in South Africa. Submitt Publ. 2016;11: e0166158. doi:10.1371/journal.pone.0166158

10. Mbuagbaw J, Jingi AM, Noubiap JJN, Kaze AD, Nansseu JRN, Bigna JJR, et al. Patterns and trends in mortality among HIV-infected and HIV-uninfected patients in a major Internal Medicine Unit in Yaounde, Cameroon: a retrospective cohort study. JRSM open. 2016;7: 2054270416654859.PubMed doi:10.1177/2054270416654859

11. Lewden C, Drabo YJ, Zannou DM, Maiga MY, Minta DK, Sow PS, et al. Disease patterns and causes of death of hospitalized HIV-positive adults in West Africa: A multicountry survey in the antiretroviral treatment era. $J$ Int AIDS Soc. 2014;17. doi:10.7448/IAS.17.1.18797

12. Assogba K, Belo M, Wateba M, Gnonlonfoun D, Ossou Inguiet P, Tsanga B., et al. Neuromeningeal cryptococcosis in sub-Saharan Africa: Killer disease with sparse data. J Neurosci Rural Pract. 2015;6: 221. doi:10.4103/09763147.153231

13. Jarvis JN, Bicanic T, Loyse A, Namarika D, Jackson A, Nussbaum JC, et al. Determinants of mortality in a combined cohort of 501 patients with HIV-associated cryptococcal meningitis: Implications for improving outcomes. Clin Infect Dis. 2014;58: 736-745. doi:10.1093/cid/cit794 14. Veltman JA, Bristow CC, Klausner JD. Review article Meningitis in HIV-positive patients in sub-Saharan Africa : a review. J Int AIDS Soc. 2014; 1-10. doi:10.7448/ IAS.17.1.19184

15. Woldeamanuel YW, Girma B. A 43-year systematic review and meta-analysis: Case-fatality and risk of death among adults with tuberculous meningitis in Africa. Journal of Neurology. 2014. pp. 851-865. doi:10.1007/s00415013-7060-6
16. Boulware DR, Meya DB, Muzoora C, Rolfes MA, Huppler Hullsiek K, Musubire A, et al. Timing of Antiretroviral Therapy after Diagnosis of Cryptococcal Meningitis. N EnglJ Med. 2014;370: 2487-PubMed ;2498. doi:10.1056/NEJMoa1312884

17. Marais S, Meintjes G, Pepper DJ, Dodd LE, Schutz C, Ismail Z, et al. Frequency, severity, and prediction of tuberculous meningitis immune reconstitution inflammatory syndrome. Clin Infect Dis. 2013;56: 450- PubMed ;460. doi:10.1093/cid/cis899

18. Wall EC, Cartwright K, Scarborough M, Ajdukiewicz KM, Goodson P, Mwambene J, et al. High Mortality amongst Adolescents and Adults with Bacterial Meningitis in Sub-Saharan Africa: An Analysis of 715 Cases from Malawi. PLoS One. 2013;8. doi:10.1371/journal. pone.0069783

19. Luma HN, Tchaleu BC, Mapoure YN, Temfack E, Doualla MS, Halle MP, et al. Toxoplasma encephalitis in HIV/AIDS patients admitted to the Douala general hospital between 2004 and 2009: a cross sectional study. BMC Res Notes. 2013;6: 146. PubMed doi:10.1186/17560500-6-146

20. Goita D, Karambe M, Dembele JP, Sogoba D, Sidibe AF, Diaby $S$, et al. [Cerebral toxoplasmosis during AIDS in the infectious diseases department of Point-G Teaching Hospital, Bamako, Mali]. Mali Med. 2012;27: 47PubMed ;50. doi:jMML.v27.i1.pg47 [pii]

21. Marais S, Pepper DJ, Schutz C, Wilkinson RJ, Meintjes G. Presentation and outcome of tuberculous meningitis in a high HIV prevalence setting. PLoS One. 2011. doi:10.1371/journal.pone.0020077

22. Berhe T, Melkamu Y, Amare A. The pattern and predictors of mortality of HIV/AIDS patients with neurologic manifestation in Ethiopia: a retrospective study. AIDS Res Ther. 2012;9: 11. PubMed doi:10.1186/17426405-9-11

23. Lawn SD, Myer L, Edwards D, Bekker L-G, Wood R. Short-term and long-term risk of tuberculosis associated with CD4 cell recovery during antiretroviral therapy in South Africa. AIDS. 2009;23: 1717-PubMed ;1725. doi:10.1097/QAD.0b013e32832d3b6d

24. Modi G, Hari K, Modi M, Mochan A. The frequency and profile of neurology in black South African HIV infected (clade C) patients - A hospital-based prospective audit. J Neurol Sci. 2007;254: 60-PubMed ;64. doi:10.1016/j.jns.2007.01.001

25. Lawn SD, Harries AD, Anglaret X, Myer L, Wood R. Early mortality among adults accessing antiretroviral 
treatment programmes in sub-Saharan Africa. AIDS. 2008;22: 1897-PubMed ;1908. doi:10.1097/QAD. 0b013e32830007cd [doi] \n00002030-200810010-00001 [pii]

26. Lawn SD, Harries AD, Wood R. Strategies to reduce early morbidity and mortality in adults receiving antiretroviral therapy in resource-limited settings. Curr Opin HIV AIDS. 2010;5: 18- PubMed ;26. doi:10.1097/COH.0b01 3e328333850f01222929-201001000-00005 [pii]

27. Alkali N, Bwala S, Nyandaiti Y, Danesi M. NeuroAIDS in sub-Saharan Africa: A clinical review. Ann Afr Med. 2013;12: 1. PubMed doi:10.4103/1596-3519.108242 28. HowlettWP, Nkya WM, Mmuni KA, Missalek WR. Neurological disorders in AIDS and HIV disease in the northern zone of Tanzania. AIDS. 1989;3: 289-PubMed ;296. Available: http://www.ncbi.nlm.nih.gov/entrez/ query.fogi? $\mathrm{cmd}=$ Retrieve $\& \mathrm{db}=$ PubMed\&dopt $=$ Citation\&list_uids $=2504233$

29. Howlett WP. Neurology in Africa [Internet]. revised. Cambridge: Cambridge University Press; 2015. Available: c

30. Siddiqi OK, Atadzhanov M, Birbeck GL, Koralnik IJ. The spectrum of neurological disorders in a Zambian tertiary care hospital. J Neurol Sci. 2010;290: 1-PubMed ;5. doi:10.1016/j.jns.2009.12.022

31. Oshinaike OO, Okubadejo NU, Ojini FI DM. The clinical spectrum of neurological manifestations in HIV/ AIDS patients on HAART at the Lagos University Teaching Hospital, Lagos, Nigeria. Nig Q J Hosp Med. 2009;19: 181-PubMed ;5.

32. Robertson K, Kopnisky K, Hakim J, Merry C, Nakasujja N, Hall C, et al. Second assessment of NeuroAIDS in Africa. J Neurovirol. 2008;14: 89-PubMed ;101. doi:10.1080/13550280701829793

33. Jowi JO, Mativo PM MS. Clinical and laboratory characteristics of hospitalised patients with neurological manifestations of HIV/AIDS at the Nairobi hospital. East Afr Med J. 2007;84: 67-PubMed ;76.

34. Nakasujja N, Musisi S, Robertson K, Wong M, Sacktor N, Ronald a. Human immunodeficiency virus neurological complications: an overview of the Ugandan experience. J Neurovirol. 2005;11 Suppl 3: 26-9. doi:10.1080/13550280500511782

35. Bhigjee AI. Neurological manifestations of HIV infection in Kwazulu-Natal South Africa. J Neurovirol. 2005;11 Suppl 1: 17-21.

36. Parry O, Mielke J, Latif a S, Ray S, Levy LF, Siziya S.
Peripheral neuropathy in individuals with HIV infection in Zimbabwe. Acta Neurol Scand. 1997;96: 218-PubMed ;222. doi:10.1111/j.1600-0404.1997.tb00272.x

37. Mielke J. Neurological complications of human immunodeficiency virus infection in Zimbabwe-2005. J Neurovirol. 2005;11 Suppl 3: 23-25. doi:10.1080/13550280500511766

38. Modi M, Mochan A, Modi G. Management of HIV-associated focal brain lesions in developing countries. QJM -Mon J Assoc Physicians. 2004;97: 413-421. doi:10.1093/ qjmed/hch080

39. Sene-Diouf F, Ndiaye M, Diop AG, Thiam A, Ndao AK, Diagne M, Ndiaye MM NI. Epidemiological, clinical and progressive aspects of neurological manifestations associated with retroviral infections: eleven year retrospective study. Dakar Med. 2000;45: 162- PubMed ;6.

40. Modi G, Modi M, Martinus I, Saffer D. New-onset seizures associated with HIV infection. Neurology. 2000;55: 1558-PubMed;1561. doi:10.1212/WNL.55.10.1558

41. Howlett WP, Luabeya MS, Kalulu N KN. AIDS in Africa. New York: Raven Press; 1994.

42. Perriens JH, Mussa M, Luabeya MK, Kayembe K, Kapita B, Brown C, et al. Neurological complications of HIV-1-seropositive internal medicine inpatients in Kinshasa,Zaire. J Acquir Immune Defic Syndr. 1992;5:333-340. Available: http://ezproxy.newcastle.edu.au/login?url=http:/ / ovidsp.ovid.com? $\mathrm{T}=\mathrm{JS} \& \mathrm{CSC}=\mathrm{Y} \& \mathrm{NEWS}=\mathrm{N} \& \mathrm{PAGE}=$ fulltext $\& D=\operatorname{med} 3 \& A N=1312594 \% 5$ Cnhttp: $/ /$ library. newcastle.edu.au/resserv?sid=OVID:medline\&id $=$ pmid :1312594\&id $=\&$ iss $n=0894-9255 \&$ isbn $=\&$ volume $=5$ \&is sue $=4 \&$ spage $=333 \&$ pages $=333-40$

43. Belec L, Testa J, Vohito MD, Gresenguet G, Martin MI, Tabo A, et al. [Neurologic and psychiatric manifestations of AIDS in Central African Republic]. Bull Soc Pathol Exot Filiales. 1989;82: 297-307.

44. Martinez-Steele E, Awasana AA, Corrah T, Sabally S, van der Sande M, Jaye A, et al. Is HIV-2- induced AIDS different from HIV-1-associated AIDS? Data from a West African clinic. AIDS. 2007;21: 317-PubMed ;24. doi:10.1097/QAD.0b013e328011d7ab

45. Choi Y, Townend J, Vincent T, Zaidi I, Sarge-Njie R, Jaye A, et al. Neurologic manifestations of human immunodeficiency virus-2: Dementia, myelopathy, and neuropathy in West Africa. J Neurovirol. 2011;17: 166-PubMed ;175. doi:10.1007/s13365-011-0022-9

46. Rajasingham R, Smith RM, Park BJ, Jarvis JN, Govender NP, Chiller TM, Denning DW, Loyse A BD. Glob- 
al burden of disease of HIV-associated cryptococcal meningitis: an updated analysis. Lancet Infect Dis. 2017; doi:10.1016/S1473-3099(17)30243-8

47. Jarvis JN, Govender N, Chiller T, Park BJ, Longley N, Meintjes G, et al. Cryptococcal Antigen Screening and Preemptive Therapy in Patients Initiating Antiretroviral Therapy in Resource-Limited Settings: A Proposed Algorithm for Clinical Implementation. I Int Assoc Physicians AIDS Care. 2012;11: 374-379. doi:10.1177/1545109712459077 48. Jarvis JN, Harrison TS. HIV-associated cryptococcal meningitis. AIDS. 2007;21: 2119-PubMed; 2129. doi:doi: 10.1097/QAD.0b013e3282a4a64d

49. Alemu AS, Kempker RR, Tenna A, Smitson C, Berhe N, Fekade D, et al. High prevalence of Cryptococcal antigenemia among HIV-infected patients receiving antiretroviral therapy in Ethiopia. PLoS One. 2013;8: e58377. doi:10.1371/journal.pone.0058377

50. Seboxa T, Alemu S, Assefa A, Asefa A, Diro E. Cryptococcal meningitis in patients with acquired immunudeficiency syndrome in prehaart era at Gondar College of Medical Sciences Hospital north-west Ethiopia. Ethiop Med J. 2010;48: 237-PubMed ;241.

51. Bamba S, Lortholary O, Sawadogo A, Millogo A, Guiguemde RT, Bretagne S. Decreasing incidence of cryptococcal meningitis in West Africa in the era of highly active antiretroviral therapy. AIDS. 2012;26: 1039-PubMed ;1041. doi:http://dx.doi.org/10.1097/ QAD.0b013e328352d1d8

52. Gomerep SS, Idoko JA, Ladep NG, Ugoya SO, Obaseki D, Agbaji OA, et al. Frequency of cryptococcal meningitis in HIV-1 infected patients in north central Nigeria. Niger J Med. 2010;19: 395- PubMed ;399.

53. Park B, Wannemuehler K, Marston B, Govedner N, Pappas P, Chiller T. Estimation o the current global burden of cryptococcal mengingitis among persons living with HIV/Aids. AIDS. 2009;23: 525-PubMed ;530. doi:10.1097/QAD.0b013e328322ffac

54. Bisson GP, Lukes J, Thakur R, Mtoni I, McGregor RR. Cryotococcus and lymphocytic meningitis in Botswana. South African Med J. 2008;98: 724-PubMed ;725.

55. Baldassarre R, Mdodo R, Omonge E, Jaoko W, Baddley J, Pappas P, et al. MORTALITY AFTER CLINICAL MANAGEMENT OF AIDS-ASSOCIATED CRYPTOCOCCAL MENINGITIS IN KENYA. East Afr Med J. 2014;91: 145- PubMed ;151.

56. Gaskell KM, Rothe C, Gnanadurai R, Goodson P, Jassi C, Heyderman RS, et al. A prospective study of mortality from cryptococcal meningitis following treatment induction with $1200 \mathrm{mg}$ oral fluconazole in Blantyre, Malawi. PLoS One. 2014. doi:10.1371/journal.pone.0110285 57. Kendi C, Penner J, Koech J, Nyonda M, Cohen CR, Bukusi EA, et al. Predictors of outcome in routine care for Cryptococcal meningitis in Western Kenya: lessons for HIV outpatient care in resource-limited settings. Postgrad Med J. 2013;89: 73-PubMed ;77. doi:10.1136/postgradmedj-2012-130823

58. Jackson A HM. Management of cryptococcal meningitis in sub-Saharan Africa. Curr HIV/AIDS Rep. 2010;73: 134- PubMed ;142.

59. Kambugu A, Meya DB, Rhein J, O'Brien M, Janoff EN, Ronald AR, et al. Outcomes of Cryptococcal Meningitis in Uganda Before and After the Availability of Highly Active Antiretroviral Therapy. Clin Infect Dis. 2008;46: 1694- PubMed ;1701. doi:10.1086/587667

60. Britz E, Perovic O, Mollendorf C von, Gottberg A von, Iyaloo S, Quan V, et al. The epidemiology of meningitis among adults in a South African province with a high HIV prevalence, 2009-2012. [Internet]. PLoS One. 2016. p. e0163036. doi:10.1371/journal.pone.0163036

61. Aoussi EF, Ehui E, Dembélé JP, Kolia-Diafouka P, Elloh NF, Ouattara SI, et al. Cryptoccocal meningitis and $\mathrm{HIV}$ in the era of HAART in C??te d'Ivoire. Med Mal Infect. 2012;42: 349-PubMed ;354. doi:10.1016/j.medmal.2012.05.012

62. Jarvis JN, Meintjes G, Williams A, Brown Y, Crede T, Harrison TS. Adult meningitis in a setting of high HIV and TB prevalence: findings from 4961 suspected cases. BMC Infect Dis. 2010;10: 67. PubMed doi:10.1186/14712334-10-67

63. Mdodo R, Brown K, Omonge E, Jaoko W, Baddley J, Pappas P, et al. The prevalence, clinical features, risk factors and outcome associated with cryptococcal meningitis in HIV positive patients in Kenya. East Afr Med J. 2010;87: 481- PubMed ;487.

64. Jarvis JN, Meintjes G, Harrison TS. Outcomes of cryptococcal meningitis in antiretroviral naïve and experienced patients in South Africa. Journal of Infection. 2010. pp. 496-498. doi:10.1016/j.jinf.2010.03.007

65. Mwaba P. Clinical presentation, natural history, and cumulative death rates of 230 adults with primary cryptococcal meningitis in Zambian AIDS patients treated under local conditions. Postgrad Med J. 2001;77: 769PubMed ;773. doi:10.1136/pmj.77.914.769

66. Heyderman RS, Gangaidzo IT, Hakim JG, Mielke J, Taziwa a, Musvaire P, et al. Cryptococcal meningitis in human immunodeficiency virus-infected patients 
in Harare, Zimbabwe. Clin Infect Dis. 1998;26: 284 PubMed ;9. Available: http://www.ncbi.nlm.nih.gov/ pubmed/9502443

67. Williams DA, Kiiza T, Kwizera R, Kiggundu R, Velamakanni S, Meya DB, et al. Evaluation of Fingerstick Cryptococcal Antigen Lateral Flow Assay in HIV-Infected Persons: A Diagnostic Accuracy Study. Clin Infect Dis. 2015;61: 464-PubMed ;467. doi:10.1093/cid/civ263

68. Rugemalila J, Maro VP, Kapanda G, Ndaro AJ, Jarvis JN. Cryptococcal antigen prevalence in HIV-infected Tanzanians: A cross-sectional study and evaluation of a point-of-care lateral flow assay. Trop Med Int Heal. 2013;18: 1075-PubMed ;1079. doi:10.1111/tmi.12157

69. Jarvis JN, Harrison TS, Lawn SD, Meintjes G, Wood R, Cleary S. Cost Effectiveness of Cryptococcal Antigen Screening as a Strategy to Prevent HIV-Associated Cryptococcal Meningitis in South Africa. PLoS One. 2013;8. doi:10.1371/journal.pone.0069288

70. Meyer ACL, Kendi CK, Penner JA, Odhiambo N, Otieno B, Omondi E, et al. The impact of routine cryptococcal antigen screening on survival among HIV-infected individuals with advanced immunosuppression in Kenya. Trop Med Int Heal. 2013;18: 495-503. doi:10.1111/ tmi.12067

71. Rajasingham R, Meya DB, Boulware DR. Integrating cryptococcal antigen screening and pre-emptive treatment into routine HIV care. J Acquir Immune Defic Syndr. 2012;59: e85-91. doi:10.1097/QAI.0b013e31824c837e

72. Wajanga BM, Kalluvya S, Downs JA, Johnson WD, Fitzgerald DW, Peck RN. Universal screening of Tanzanian HIV-infected adult inpatients with the serum cryptococcal antigen to improve diagnosis and reduce mortality: An operational study. J Int AIDS Soc. 2011;14. doi:10.1186/1758-2652-14-48

73. Meda J, Kalluvya S, Downs JA, Chofle AA, Seni J, Kidenya B, et al. Cryptococcal Meningitis Management in Tanzania with Strict Schedule of Serial Lumber Punctures using Intravenous Tubing Sets. JAIDS J Acquir Immune Defic Syndr. 2014; 1. doi:10.1097/QAI.0000000000000147 74. Nussbaum JC, Jackson A, Namarika D, Phulusa J, Kenala J, Kanyemba C, et al. Combination Flucytosine and High-Dose Fluconazole Compared with Fluconazole Monotherapy for the Treatment of Cryptococcal Meningitis: A Randomized Trial in Malawi. Clin Infect Dis. 2010;50: 338-PubMed ;344. doi:10.1086/649861

75. Bicanic T, Wood R, Meintjes G, Rebe K, Brouwer A, Loyse A, et al. High-Dose Amphotericin B with Flu- cytosine for the Treatment of Cryptococcal Meningitis in HIV-Infected Patients: A Randomized Trial. Clin Infect Dis. 2008;47: 123- PubMed ;130. doi:10.1086/588792

76. Walker NF, Scriven J, Meintjes G, Wilkinson RJ. Immune reconstitution inflammatory syndrome in HIV-infected patients. HIV AIDS (Auckl). 2015;7: 49-64. doi:10.2147/HIV.S42328

77. Lawn SD, Zumla AI. Tuberculosis. Lancet. 2011;378: 57-PubMed ;72. doi:10.1016/S0140-6736(10)62173-3

78. Marais S, Pepper DJ, Marais BJ, Török ME. HIV-associated tuberculous meningitis - Diagnostic and therapeutic challenges. Tuberculosis. 2010. pp. 367-374. doi:10.1016/j. tube.2010.08.006

79. Bhagwan S, Naidoo K. Aetiology, clinical presentation, and outcome of meningitis in patients coinfected with human immunodeficiency virus and tuberculosis. AIDS Res Treat. 2011;2011. doi:10.1155/2011/180352

80. Cohen DB, Zijlstra EE, Mukaka M, Reiss M, Kamphambale S, Scholing M, et al. Diagnosis of cryptococcal and tuberculous meningitis in a resource-limited African setting. Trop Med Int Heal. 2010;15: 910- PubMed ;917. doi:10.1111/j.1365-3156.2010.02565.x

81. Cox JA, Lukande RL, Kalungi S, Van Marck E, Lammens M, Van De Vijver K, et al. Accuracy of lipoarabinomannan and xpert MTB/RIF testing in cerebrospinal fluid to diagnose tuberculous meningitis in an autopsy cohort of HIV-infected adults. J Clin Microbiol. 2015;53: 2667- PubMed ;2673. doi:10.1128/JCM.00624-15

82. Bahr NC, Tugume L, Rajasingham R, Kiggundu R, Williams DA, Morawski B, et al. Improved diagnostic sensitivity for tuberculous meningitis with Xpert ${ }^{\circledR}$ MTB/ RIF of centrifuged CSF. Int J Tuberc Lung Dis. 2015;19: 1209-1215. doi:10.5588/ijtld.15.0253

83. Patel VB, Theron G, Lenders L, Matinyena B, Connolly C, Singh R, et al. Diagnostic Accuracy of Quantitative PCR (Xpert MTB/RIF) for Tuberculous Meningitis in a High Burden Setting: A Prospective Study. PLoS Med. 2013;10. doi:10.1371/journal.pmed.1001536

84. Meybeck A, Calbet J, Ruimy R, Mashri K, Jachym M, Joly $\mathrm{V}$, et al. Multidrug-Resistant Tuberculous Meningitis in an HIV-Positive Patient: A Challenging Disease. AIDS Patient Care STDS. 2007;21: 149-153. doi:10.1089/ apc. 2006.0058

85. Pepper DJ, Marais S, Maartens G, Rebe K, Morroni C, Rangaka MX, et al. Neurologic manifestations of paradoxical tuberculosis-associated immune reconstitution inflammatory syndrome: a case series. Clin Infect Dis. 2009;48: e96-107. doi:10.1086/598988 
86. Manga NM, Ndour CT, Diop SA, Ka-Sall R, Dia NM, Seydi M, et al. Adult purulent meninggitis caused by Streptococcus pneumoniae in Dakar, Senegal [Internet]. Medecine Tropicale. 2008. pp. 625-628. Available: http:// ovidsp.ovid.com/ovidweb.cgi? $\mathrm{T}=\mathrm{JS} \& \mathrm{PAGE}=$ reference $\& D=$ emed $8 \& N E W S=N \& A N=2009098579$

87. Zeleke AJ MY. Seroprevalence of Toxoplasma gondii and associated risk factors among HIV-infected women within reproductive age group at Mizan Aman General Hospital, Southwest Ethiopia: a cross sectional study. BMC Res Notes. 2017;10: 70.

88. Gebremedhin EZ, Tadesse G. A meta-analysis of the prevalence of Toxoplasma gondii in animals and humans in Ethiopia. Parasit Vectors. 2015;8: 291. PubMed doi:10.1186/s13071-015-0901-7

89. Ogoina D, Obiako RO, Onyemelukwe GC, Musa BO, Hamidu a U. Clinical presentation and outcome of toxoplasma encephalitis in HIV-infected patients from Zaria, Northern Nigeria: a case series of $9 \mathrm{pa}-$ tients. J Int Assoc Provid AIDS Care. 2014;13: 18-21. doi:10.1177/2325957413500529

90. Hari KR, Modi MR, Mochan AHD, Modi G. Reduced risk of toxoplasma encephalitis in HIV-infected patients - a prospective study from Gauteng, South Africa. Int J STD AIDS. 2007;18: 555-PubMed;558. doi:10.1258/095646207781439829

91. Ondounda M, Ilozue C, Magne C. Cerebro-meningeal infections in HIV-infected patients: A study of 116 cases in Libreville, Gabon. Afr Health Sci. 2016;16: 603PubMed ;610. doi:10.4314/ahs.v16i2.31

92. Oshinaike OO, Okubadejo NU, Ojini FI, Danesi MA. A preliminary study of the frequency of focal neurological deficits in HIV/AIDS patients seropositive for Toxoplasma gondii IgG in Lagos, Nigeria. NigQJHospMed. 2010;20: 104-PubMed ;107. Available: http://ovidsp.ovid.com/ ovidweb.cgi? $\mathrm{T}=\mathrm{JS} \& \mathrm{CSC}=\mathrm{Y} \& \mathrm{NEWS}=\mathrm{N} \& \mathrm{PAGE}=-$ fulltext\&D=med5\&AN=21033315http:/ /sfx.scholarsportal.info/uhn?sid=OVID:medline\&id=pmid:21033315\&id=doi: \&issn=0189-2657\&isb$\mathrm{n}=\&$ volume $=20 \&$ is sue $=3 \&$ spage $=104 \&$ pag es $=104-7 \&$ date $=2010 \&$ title $=$ Nigerian + Quarte

93. M D, N L. Management of toxoplasmic encephalitis in HIV-infected adults ( with an emphasis on resource-poor settings ) (Review ). Library (Lond). 2008;98: 3-5. doi:10.1002/14651858.CD005420.pub2.Copyright

94. Murdoch DM, Venter WDF, Feldman C, Van Rie A.
Incidence and risk factors for the immune reconstitution inflammatory syndrome in HIV patients in South Africa: a prospective study. AIDS. 2008;22: 601-PubMed ;10. doi:10.1097/QAD.0b013e3282f4a607

95. Müller, Wandel, Colebunders, Attia, Furrer, Egger, et al. Immune reconstitution inflammatory syndrome in patients starting antiretroviral therapy for HIV infection: a systematic review and meta-analysis. Lancet Infect Dis. 2010;10: 251-PubMed ;261. doi:10.1016/S14733099(10)70026-8

96. Lawn SD. Immune reconstitution disease associated with parasitic infections following initiation of antiretroviral therapy. Curr Opin Infect Dis. 2007;20: 482-8. doi:10.1097/QCO.0b013e3282a6463d

97. Lawn SD, Myer L, Orrell C, Bekker L-G, Wood R. Early mortality among adults accessing a community-based antiretroviral service in South Africa: implications for programme design. AIDS. 2005;19: 2141PubMed ;2148. doi:10.1097/01.aids.0000194802.89540. e1

98. Marais S, Lai RPJ, Wilkinson KA, Meintjes G, O'Garra A WR. Inflammasome Activation Underlying Central Nervous System Deterioration in HIV-Associated Tuberculosis. J Infect Dis. 2017;215: 677-PubMed ;686. doi:10.1093/infdis/jiw561

99. Lynn WA, Lightman S. Syphilis and HIV: A dangerous combination. Lancet Infectious Diseases. 2004. pp. 456466. doi:10.1016/S1473-3099(04)01061-8

100. Shimelis T, Lemma K, Ambachew H, Tadesse E. Syphilis among people with HIV infection in southern Ethiopia: sero-prevalence and risk factors. BMC Infect Dis. 2015;15: 189. PubMed doi:10.1186/s12879-015-0919-7 101. Tattevin P, Renault P, Joly V, Bastos R, Coelho E, Adda C, et al. Treatment of latent syphilis in HIV-infected patients with $10 \mathrm{~d}$ of benzylpenicillin $\mathrm{G}$ benethamine: a prospective study in Maputo, Mozambique. Scand J Infect Dis. 2002;34: 257-PubMed ;261. doi:10.1080/00365540110077380

102. Nnoruka EN, Ezeoke ACJ. Evaluation of syphilis in patients with HIV infection in Nigeria. Trop Med Int Heal. 2005;10: 58-PubMed ;64. doi:10.1111/j.13653156.2004.01344.x

103. Bhigjee a I, Madurai S, Bill PL, Patel V, Corr P, Naidoo MN, et al. Spectrum of myelopathies in HIV seropositive South African patients. Neurology. 2001;57: 348-PubMed ;351. doi:10.1212/WNL.57.2.348 
104. Schutte CM, Townsend T, Van Coller R, Olorunju S. Comparison of HTLV-associated myelopathy (HAM) in HIV-positive and HIV-negative patients at a tertiary South African hospital. South African Med J. 2013;103: 43PubMed ;46. doi:10.7196/SAMJ.5298

105. Karp G, Schlaeffer F, Jotkowitz A, Riesenberg K. Syphilis and HIV co-infection. European Journal of Internal Medicine. 2009. pp. 9-13. doi:10.1016/j.ejim.2008.04.002 106. Mwamba PM, Mwanda WO, Busakhala NW, Strother RM, Loehrer PJ, Remick SC. AIDS-Related Non-Hodgkin's Lymphoma in Sub-Saharan Africa: Current Status and Realities of Therapeutic Approach. Lymphoma. 2012;2012: 1-PubMed ;9. doi:10.1155/2012/904367

107. Tan IL, Smith BR, von Geldern G, Mateen FJ, McArthur JC. HIV-associated opportunistic infections of the CNS. The Lancet Neurology. 2012. pp. 605-617. doi:10.1016/S1474-4422(12)70098-4

108. Bain LE, Kum AP, Ekukwe NC, Clovis NC, Enowbeyang TE. HIV, cardiovascular disease, and stroke in sub-Saharan Africa. The Lancet HIV. 2016. pp. e341e342. doi:10.1016/S2352-3018(16)30092-3

109. Modi G, Modi M, Mochan A. Is stroke a HIV-related neurologic manifestation? Expert Rev Neurother. 2008;8: 1247-53. doi:10.1586/14737175.8.8.1247

110. Walker RW, Jusabani A, Aris E, Gray WK, Unwin $\mathrm{N}$, Swai M, et al. Stroke risk factors in an incident population in urban and rural Tanzania: A prospective, community-based, case-control study. Lancet Glob Heal. 2013;1. doi:10.1016/S2214-109X(13)70068-8

111. AI Q, RS J, JM K, al et. HUman immunodeficiency virus infection and stroke in young patients. Arch Neurol. 1997;54: 1150-PubMed ;1153. Available: http://dx.doi. org/10.1001/archneur.1997.00550210078016

112. VB P, Sacoor Z, Francis P, PLA B, AI B, Connolly $\mathrm{C}$. Ischemic stroke in young HIV-positive patients in Kwazulu-Natal, South Africa. Neurology. 2005;65: 759_ PubMed ;761 3p.

113. Mochan A, Modi M, Modi G. Stroke in black South African HIV-positive patients: a prospective analysis. Stroke. 2003;34: 10-PubMed ;15. doi:10.1161/01. STR.0000043821.35051.FA

114. Hoffmann M, Berger JR, Nath a, Rayens M. Cerebrovascular disease in young, HIV-infected, black Africans in the KwaZulu Natal province of South Africa. J Neurovirol. 2000;6: 229- PubMed ;36. doi:10.3109/13550280009015825

115. Mapoure YN, Nkongni IN, Luma HN, Ngahane BHM, Barla E, Ngwane S, et al. [ncidence of strokes in HIV-positive patients treated with long term antiretroviral treatment]. Pan Afr Med J. 2016;24: 45. PubMed doi:10.11604/pamj.2016.24.45.8013 PubMed

116. Tipping B, de Villiers L, Wainwright H, Candy S, Bryer A. Stroke in patients with human immunodeficiency virus infection. J Neurol Neurosurg Psychiatry. 2007;78: 1320-1324. doi:10.1136/jnnp.2007.116103

117. Benjamin LA, Corbett EL, Connor MD, Mzinganjira H, Kampondeni S, Choko A, et al. HIV, antiretroviral treatment, hypertension, and stroke in Malawian adults. Neurology. 2016;86: 324-PubMed ;333. doi:10.1212/ WNL.0000000000002278

118. Luchuo EB, Nkoke C. A new look at human immunodeficiency virus infection and stroke in Sub-Saharan Africa. Ann Transl Med. 2016;4: 246. PubMed doi:10.21037/atm.2016.06.15

119. Siddiqi OK, Elafros MA, Bositis CM, Koralnik IJ, Theodore WH, Okulicz JF, et al. New-onset seizure in HIV-infected adult Zambians A search for causes and consequences. Neurology. 2017;88: 477-482. doi:10.1212/ WNL.0000000000003538

120. Sikazwe I, Elafros MA, Bositis CM, Siddiqi OK, Koralnik IJ, Kalungwana L, et al. HIV and new onsetseizures: Slipping through the cracks in HIV care and treatment. HIV Med. 2016;17: 118-123. doi:10.1111/ hiv.12283

121. Ba-Diop A, Marin B, Druet-Cabanac M, Ngoungou EB, Newton CR, Preux PM. Epidemiology, causes, and treatment of epilepsy in sub-Saharan Africa. Lancet Neurol. 2014;13: 1029-PubMed ;1044. doi:10.1016/S14744422(14)70114-0

122. Siddiqi O, Birbeck GL. Safe treatment of seizures in the setting of HIV/AIDS. Curr Treat Options Neurol. 2013;15: 529-543. doi:10.1007/s11940-013-0237-6

123. Modi M, Mochan A, Modi G. New onset seizures in HIV--seizure semiology, CD4 counts, and viral loads. Epilepsia. 2009;50: 1266-PubMed ;1269. doi:10.1111/j.15281167.2008.01942.x

124. Kellinghaus C, Engbring C, Kovac S, Möddel G, Boesebeck F, Fischera M, et al. Frequency of seizures and epilepsy in neurological HIV-infected patients. Seizure. 2008;17: 27-33. doi:10.1016/j.seizure.2007.05.017 125. Preux PM, Druet-Cabanac M. Epidemiology and aetiology of epilepsy in sub-Saharan Africa. Lancet Neurology. 2005. pp. 21-31. doi:10.1016/S1474-4422(04)00963-9 126. Garg RK. HIV medicine: HIV infection and seizures. Postgrad Med J. 1999;75: 387-PubMed ;390. doi:10.1136/ pgmj.75.885.387 
127. Habib AG, Yakasai AM, Owolabi LF, Ibrahim A, Habib ZG, Gudaji M, et al. Neurocognitive impairment in HIV-1-infected adults in Sub-Saharan Africa: a systematic review and meta-analysis. Int J Infect Dis. 2013;17: e820-31. doi:10.1016/j.ijid.2013.06.011

128. Goodkin K, Hardy DJ, Singh D, Lopez E. Diagnostic Utility of the International HIV Dementia Scale for HIV-Associated Neurocognitive Impairment and Disorder in South Africa. J Neuropsychiatry Clin Neurosci. 2014;26: 352-358. doi:10.1176/appi.neuropsych.13080178

129. Joska J a, Westgarth-Taylor J, Hoare J, Thomas KGF, Paul R, Myer L, et al. Neuropsychological outcomes in adults commencing highly active anti-retroviral treatment in South Africa: a prospective study. BMC Infect Dis. 2012;12: 39. PubMed doi:10.1186/1471-2334-12-39

130. Kabuba N, Anitha Menon J, Franklin DR Jr, Heaton RK HK. AIDS Use of Western Neuropsychological Test Battery in Detecting HIV-Associated Neurocognitive Disorders (HAND) in Zambia. Behav. 2017;21: 1717 PubMed ;1727. doi:10.1007/s10461-016-1443-5

131. Robertson K, Jiang H, Evans SR, Marra CM, Berzins B, Hakim J, et al. International neurocognitive normative study: neurocognitive comparison data in diverse resource-limited settings: AIDS Clinical Trials Group A5271. J Neurovirol. 2016;22: 472-PubMed ;478. doi:10.1007/s13365-015-0415-2

132. Robertson KR, Hall CD. Assessment of neuroAIDS in the international setting. Journal of Neuroimmune Pharmacology. 2007. pp. 105-111. doi:10.1007/s11481-0069052-0

133. Robertson K, Liner J, Hakim J, Sankalé J-L, Grant I, Letendre S, et al. NeuroAIDS in Africa. J Neurovirol. 2010;16: 189-PubMed ;202. doi:10.3109/13550284.2010 .489597

134. Meyer A-C. Neurology and the Global HIV Epidemic. Semin Neurol. 2014;34: 70-PubMed ;7. doi:10.1055/s-0034-1372344

135. Patel VN, Mungwira RG, Tarumbiswa TF, Heikinheimo T, van Oosterhout JJ. High prevalence ofsuspected HIV-associated dementia in adult Malawian HIV patients. Int J STD AIDS. 2010;21: 356- PubMed ;8. doi:10.1258/ ijsa.2010.009554

136. Holguin A, Banda M, Willen EJ, Malama C, Chiyenu KO, Mudenda VC, et al. HIV-1 effects on neuropsychological performance in a resource-limited country, Zambia. AIDS Behav. 2011;15: 1895-PubMed ;1901. doi:10.1007/s10461-011-9988-9
137. Nakku J, Kinyanda E, Hoskins S. Prevalence and factors associated with probable HIV dementia in an African population: A cross-sectional study of an HIV/ AIDS clinic population. BMC Psychiatry. 2013;13: 126. PubMed doi:10.1186/1471-244X-13-126

138. Atashili J, Gaynes BN, Pence BW, Tayong G, Kats $\mathrm{D}$, O'donnell JK, et al. Prevalence, characteristics and correlates of a positive-dementia screen in patients on antiretroviral therapy in Bamenda, Cameroon: a cross-sectional study. BMC Neurol. 2013;13: 86. PubMed doi:10.1186/1471-2377-13-86

139. Howlett WP, Nkya WM, Kvale G, Nilssen S. The snout and palmomental reflexes in HIV disease in Tanzania. Acta Neurol Scand. 1995;91: 470- PubMed ;476. doi:10.1111/j.1600-0404.1995.tb00448.x

140. Joseph J, Achim CL, Boivin MJ, Brew BJ, Clifford DB, Colosi DA, et al. Global NeuroAIDS roundtable. Journal of NeuroVirology. 2013. pp. 1-9. doi:10.1007/ s13365-012-0143-9

141. Sacktor N, Nakasujja N, Skolasky RL, Rezapour M, Robertson K, Musisi S, et al. HIV subtype D is associated with dementia, compared with subtype A, in immunosuppressed individuals at risk of cognitive impairment in Kampala, Uganda. Clin Infect Dis. 2009;49: 780- PubMed ;6. doi:10.1086/605284

142. Buch S, Chivero ET, Hoare J, Jumare J, Nakasujja N, Mudenda V, et al. Proceedings from the NIMH symposium on "NeuroAIDS in Africa: neurological and neuropsychiatric complications of HIV." J Neurovirol. 2016;22: 699-PubMed ;702.doi:10.1007/s13365-016-0467-y

143. Sacktor N, Nakasujja N, Redd AD, Manucci J, Laeyendecker O, Wendel SK, et al. HIV subtype is not associated with dementia among individuals with moderate and advanced immunosuppression in Kampala, Uganda. Metab Brain Dis. 2014;29: 261-PubMed ;268. doi:10.1007/ s11011-014-9498-3

144. Sacktor N, Nakasujja N, Okonkwo O, Skolasky RL, Robertson K, Musisi S, et al. Longitudinal neuropsychological test performance among HIV seropositive individuals in Uganda. J Neurovirol. 2013;19: 48- PubMed ;56. doi:10.1007/s13365-012-0139-5

145. Brew BJ, Chan P. Update on HIV dementia and $\mathrm{HIV}$-associated neurocognitive disorders. Current Neurology and Neuroscience Reports. 2014. doi:10.1007/s11910-0140468-2

146. Clifford DB, Ances BM. HIV-associated neurocognitive disorder. The Lancet Infectious Diseases. 2013. pp. 6-86. doi:10.1016/S1473-3099(13)70269-X 
147. Njamnshi AK, Bissek ACZ-K, Ongolo-Zogo P, Tabah EN, Lekoubou AZ, Yepnjio FN, et al. Risk factors for HIV-associated neurocognitive disorders (HAND) in sub-Saharan Africa: the case of Yaounde-Cameroon. J Neurol Sci. 2009;285: 149- PubMed ;153. doi:10.1016/j. jns.2009.06.043

148. Wong MH, Robertson K, Nakasujja N, Skolasky R, Musisi S, Katabira E, et al. Frequency of and risk factors for HIV dementia in an HIV clinic in sub-Saharan Africa. Neurology. 2007;68: 350-355. doi:10.1212/01. wnl.0000252811.48891.6d

149. Centner CM, Bateman KJ, Heckmann JM. Manifestations of HIV infection in the peripheral nervous system. The Lancet Neurology. 2013. pp. 295-309. doi:10.1016/ S1474-4422(13)70002-4

150. Mehta SA, Ahmed A, Kariuki BW, Said S, Omasete $\mathrm{F}$, Mendillo $\mathrm{M}$, et al. Implementation of a validated peripheral neuropathy screening tool in patients receiving antiretroviral therapy in Mombasa, Kenya. Am J Trop Med Hyg. 2010;83: 565-PubMed ;570. doi:10.4269/ajtmh.2010.09-0629

151. Woldeamanuel YW, Kamerman PR, Veliotes DGA, Phillips TJ, Asboe D, Boffito M, et al. Development, validation, and field-testing of an instrument for clinical assessment of HIV-associated neuropathy and neuropathic pain in resource-restricted and large population study settings. PLoS One. 2016;11. doi:10.1371/journal. pone.0164994

152. Mullin S, Temu A, Kalluvya S, Grant A, Manji H. High prevalence of distal sensory polyneuropathy in antiretroviral-treated and untreated people with HIV in Tanzania. Trop Med Int Heal. 2011;16: 1291-PubMed ;1296. doi:10.1111/j.1365-3156.2011.02825.x

153. Maritz J, Benatar M, Dave JA, Harrison TB, Badri M, Levitt NS, et al. HIV neuropathy in South Africans: Frequency, characteristics, and risk factors. Muscle Nerve. 2010; NA-NA. doi:10.1002/mus.21535

154. Evans D, Takuva S, Rassool M, Firnhaber C, Maskew M. Prevalence of peripheral neuropathy in antiretroviral therapy naive HIV-positive patients and the impact on treatment outcomes--a retrospective study from a large urban cohort in Johannesburg, South Africa. J Neurovirol. 2012;18: 162-PubMed ;171. doi:10.1007/s13365-0120093-2

155. Tumusiime DK, Venter F, Musenge E, Stewart A. Prevalence of peripheral neuropathy and its associated demographic and health status characteristics, among people on antiretroviral therapy in Rwanda. BMC Public Health. 2014;14: 1306. PubMed doi:10.1186/1471-245814-1306

156. Ekenze OS, Nwosu CM, Ogunniyi A. Frequency and risk factors for distal sensory polyneuropathy in HIV infection in a developing country. Int J STD AIDS. 2014;25: 178-PubMed ;183. doi:10.1177/0956462413498226

157. Kiwuwa-Muyingo S, Kikaire B, Mambule I, Musana $H$, Musoro G, Gilks CF, et al. Prevalence, incidence and predictors of peripheral neuropathy in African adults with HIV infection within the DART trial. AIDS. 2014;28: 2579-PubMed ;2588. doi:10.1097/ QAD.0000000000000447

158. McGrath CJ, Njoroge J, John-Stewart GC, Kohler PK, Benki-Nugent SF, Thiga JW, et al. Increased incidence of symptomatic peripheral neuropathy among adults receiving stavudine- versus zidovudine-based antiretroviral regimens in Kenya. In: Journal of Neurovirology. [Internet]. 2012 pp. 200-4. doi:10.1007/s13365-012-0098-x

159. Sacktor N, Nakasujja N, Skolasky RL, Robertson K, Musisi S, Ronald A, et al. Benefits and risks of stavudine therapy for $\mathrm{HIV}$-associated neurologic complications in Uganda. Neurology. 2009;72: 165- PubMed ;170. doi:10.1212/01.wnl.0000339042.96109.86

160. Millogo A, Lankoande D, Yameogo I, Yameogo AA, Sawadogo AB. [Polyneuropathies in patients treated with HAART in Bobo-Dioulasso hospital, Burkina Faso]. Bull Soc Pathol Exot. 2008;101: 11-13.

161. Centner CM, Little F van der Watt JJ, Vermaak JR, Dave JA, Levitt NS HJ. Evolution of sensory neuropathy after initiation of antiretroviral therapy. Muscle Nerve. Muscle Nerve. 2017; doi:doi: 10.1002/mus.25710

162. Arenas-Pinto A, Thompson J, Musoro G, Musana H, Lugemwa A, Kambugu A, et al. Peripheral neuropathy in HIV patients in sub-Saharan Africa failing firstline therapy and the response to second-line ART in the EARNEST trial. I Neurovirol. 2016;22: 104- PubMed ;113. doi:10.1007/s13365-015-0374-7

163. Obiako OR, Ogoina D, Abubakar SA, Muktar HM, Sheikh TL, Tabi-Ajayi E, et al. The frequency and outcome of neuropathies among HIV/AIDS adults treated at a tertiary hospital in Kaduna State, Nigeria. Niger Postgrad Med J. 2014;21: 319-326. Available: http:// ovidsp.ovid.com/ovidweb.cgi? $\mathrm{T}=\mathrm{JS} \& \mathrm{PAGE}=$ reference $\& \mathrm{D}=$ medl $\& N E W S=\mathrm{N} \& A N=25633451$

164. Obiako OR, Abdu-Aguye I, Ogunniyi A. Effect of stavudine-based antiretroviral therapy on the severity of 
polyneuropathy in HIV/AIDS patients: a preliminary report from Zaria, Northern Nigeria. West Afr J Med. 2011;30: 354 - PubMed ;358.

165. Komolafe M, Fatusi O, Alatise O, Komolafe E, Amusa Y, Adeolu A, et al. The role of human immunodeficiency virus infection in infranuclear facial paralysis. $J$ Natl Med Assoc. 2009;101: 361- PubMed ;366. Available: papers2://publication/uuid/5129A3C2-4A6B-41938951-F74CE9E14F62

166. Millogo A, Sawadogo AB, Sawadogo AP, Lankoandé D. Peripheral neuropathies revealing HIV infection at the Hospital Center of Bobo-Dioulasso (Burkina Faso). Bull Soc Pathol Exot. 2002;95: 27-30.

167. Belec L, Georges AJ, Bouree P, Schuller E, Vuillecard E, Di Costanzo B, et al. Peripheral facial nerve palsy related to HIV infection: relationship with the immunological status and the HIV staging in Central Africa. Cent Afr J Med. 1991;37: 88- PubMed ;93.

168. Van de Perre P, Bakkers E, Batungwanayo J, Kestelyn P, Lepage P, Nzaramba D, et al. Herpes zoster in African patients: an early manifestation of HIV infection. Scand J Infect Dis. 1988;20: 277- PubMed ;82. Available: http://www.ncbi.nlm.nih.gov/pubmed/3406666

169. Millogo A, Ki-Zerbo GA, Sawadogo A-B, Ouedraogo I, Tamini MM. Compared characteristics of peripheral facial paralysis according to the HIV status in Bobo-Dioulasso, Burkina Faso. Bull la Soc Pathol Exot. 2000;93: 104-107. Available: http://www.scopus.com/inward/ record.url?eid $=2-\mathrm{s} 2.0-0034168222 \&$ partnerID $=40 \& \mathrm{~m}-$ $\mathrm{d} 5=\mathrm{e} 32 \mathrm{f} 2 \mathrm{~b} 866 \mathrm{bdeec} 09 \mathrm{ec} 128 \mathrm{ecdac} 7 \mathrm{~d} 3 \mathrm{a} 8 \mathrm{e}$

170. Le Corre A, Robin A, Maalouf T, Angioi K. [Recurrent unilateral optic neuropathy associated with human immunodeficiency virus (HIV)]. J Fr Ophtalmol. 2012;35: 272- PubMed ;6.doi:10.1016/j.jfo.2011.07.015

171. Modi G, Ranchhod J, Hari K, Mochan A MM. Non-traumatic myelopathy at the Chris Hani Baragwaneth Hospital, South Africa--the influence of HIV. QJM. 2011;104: 697-PubMed ;703. doi:doi: 10.1093/ qjimed/hcr038

172. Candy S, Chang G, Andronikou S. Acute myelopathy or cauda equina syndrome in HIV-positive adults in a tuberculosis endemic setting: MRI, clinical, and pathologic findings. Am J Neuroradiol. 2014;35: 1634- PubMed ;1641. doi:10.3174/ajnr.A3958

173. Lekoubou Looti AZ, Kengne AP, Djientcheu V d. P, Kuate CT, Njamnshi AK. Patterns of non-traumatic myelopathies in Yaounde (Cameroon): a hospital based study. J Neurol Neurosurg Psychiatry. 2010;81: 768-770. doi:10.1136/jnnp.2009.177519

174. Sikalengo G, Ramirez A, Faini D, Mwamelo K, Battegay M, Jugheli L, et al. Tuberculous spondylitis diagnosed through Xpert MTB/RIF assay in urine: a case report. BMC Infect Dis. 2016;16: 514. PubMed doi:10.1186/ s12879-016-1844-0

175. Virot E, Duclos A, Adelaide L, Miailhes P, Hot A, Ferry T, et al. Autoimmune diseases and HIV infection: A cross-sectional study. Med. 2017;96: e5769. doi:10.1097/ md.0000000000005769

176. Naidoo A, Paruk H, Bhagwan B, Moodley A. Atypical presentations of acute disseminated encephalomyelitis (ADEM) in HIV infection. J Neurovirol. 2017;23: 160PubMed ;170. doi:10.1007/s13365-016-0481-0

177. Mombaur B, Lesosky MR, Liebenberg L, Vreede H, Heckmann JM. Incidence of acetylcholine receptor-antibody-positive myasthenia gravis in South Africa. Muscle and Nerve. 2015;51: 533-537. doi:10.1002/mus.24348

178. Sherpa M, Metai RK, Kumar V, Hirachan T, Ahmed KU AS. Comorbid Human Immunodeficiency Virus (HIV) and Muscle-Specific Kinase (MuSK) Myasthenia GravisNo Title. Am J Case Rep. 2017;20: 427-30.

179. Howlett WP, Vedeler CA, Nyland H, Aarli JA. Guillain-Barré syndrome in northern Tanzania: a comparison of epidemiological and clinical findings with western Norway. Acta Neurol Scand. 1996;93: 44.

180. Millogo A, Sawadogo A, Lankoande D, Sawadogo AB. [Guillain-Barre syndrome in HIV-infected patients at Bobo-Dioulasso Hospital (Burkina Faso)]. Rev Neurol. 2004;160: 559- PubMed ;562. doi:MDOI-RN-05-2004160-5-0035-3787-101019-ART08 [pii]

181. Thornton CA, Latif AS, Emmanuel JC. Guillain-Barré syndrome associated with human immunodeficiency virus infection in Zimbabwe. Neurology. 1991;41: 812- PubMed ;5. Available: http://www.ncbi.nlm.nih. gov/pubmed/2046921

182. Brannagan 3rd TH, Zhou Y. HIV-associated Guillain-Barre syndrome. J Neurol Sci. 2003;208: 39-PubMed ;42. doi:S0022510X02004185 [pii]

183. Mochan A, Anderson D, Modi G. CIDP in a HIV endemic population: A prospective case series from Johannesburg, South Africa. J Neurol Sci. 2016;363: 39PubMed ;42. doi:10.1016/j.jns.2015.11.013

184. Lucas SB, De Cock KM, Hounnou A, Peacock C, Diomande $\mathrm{M}$, Honde $\mathrm{M}$, et al. Contribution of tuberculosis to slim disease in Africa. BMJ. 1994;308: 1531PubMed ;1533. doi:10.1136/bmj.308.6943.1531 
185. Heckmann JM, PillayK, Hearn AP, Kenyon C. Polymyositis in African HIV-infected subjects. Neuromuscul Disord. 2010;20: 735- PubMed ;739. doi:10.1016/j. nmd.2010.06.007

186. Ogoina D, Umar A, Obiako OR. Dermatomyositis associated with HIV-1 infection in a Nigerian adult female: A case report. Afr Health Sci. 2012;12: 74 - PubMed ;76.

187. Lundgren JD, Babiker AG, Gordin F, Emery S, Grund B, Sharma S, et al. Initiation of Antiretroviral Therapy in Early Asymptomatic HIV Infection. $N$ Engl J Med. 2015;373: 795-807. doi:10.1056/NEJMoa1506816

188. Danel C, Moh R, Gabillard D, Badje A, Le Carrou J, Ouassa T, et al. A Trial of Early Antiretrovirals and Isoniazid Preventive Therapy in Africa. $N$ Engl J Med. 2015;373: 808-822. doi:10.1056/NEJMoa1507198

189. Longley N, Jarvis JN, Meintjes G, Boulle A, Cross A, Kelly N, et al. Cryptococcal Antigen Screening in Patients Initiating ART in South Africa: A Prospective Cohort Study. Clin Infect Dis. 2016;62: 581- PubMed ;587. doi:10.1093/cid/civ936

190. Adams P. Cryptococcal meningitis: A blind spot in curbing AIDS. Lancet. 2016;387: 1605- PubMed ;1606. doi:10.1016/S0140-6736(16)30250-1

191. Lawn SD, Wood R. Point-of-care urine antigen screening tests for tuberculosis and cryptococcosis: Po- tential for mortality reduction in antiretroviral treatment programs in Africa. Clinical Infectious Diseases. 2012. pp. 739-740. doi:10.1093/cid/cir908

192. Williamson PR, Jarvis JN, Panackal AA, Fisher MC, Molloy SF, Loyse A, et al. Cryptococcal meningitis: epidemiology, immunology, diagnosis and therapy. Nat Rev Neurol. 2016; doi:10.1038/nrneurol.2016.167

193. Mfinanga S, Chanda D, Kivuyo SL, Guinness L, Bottomley C, Simms V, et al. Cryptococcal meningitis screening and community-based early adherence support in people with advanced HIV infection starting antiretroviral therapy in Tanzania and Zambia: An open-label, randomised controlled trial. Lancet. 2015;385: 2173- PubMed ;2182. doi:10.1016/S0140-6736(15)60164-7

194. Charles MK, Lindegren M Lou, Wester CW, Blevins M, Sterling TR, Dung NT, et al. Implementation of Tuberculosis Intensive Case Finding, Isoniazid Preventive Therapy, and Infection Control (\&quot;Three I's\&quot;) and HIV-Tuberculosis Service Integration in Lower Income Countries. PLoS One. 2016;11: e0153243. doi:10.1371/journal.pone.0153243

195. Harries AD, Lawn SD, Suthar AB, Granich R. Benefits of combined preventive therapy with co-trimoxazole and isoniazid in adults living with HIV: time to consider a fixed-dose, single tablet coformulation. The Lancet Infectious Diseases. 2015. pp. 1492-1496. PubMed doi:10.1016/ S1473-3099(15)00242-X 